\title{
Using Landscape Theory to Analyze Mobile OS Platform Adoption by Mobile Device Manufacturers
}

\author{
by
}

Shruti Satsangi

A thesis submitted to the Faculty of Graduate and Postdoctoral Affairs in partial fulfillment of the requirements for the degree of

\author{
Master of Applied Science \\ in \\ Technology Innovation Management \\ Carleton University \\ Ottawa, Ontario \\ (C) 2012 \\ Shruti Satsangi
}


Library and Archives

Canada

Published Heritage

Branch

395 Wellington Street

Ottawa ON K1A ON4

Canada
Bibliothèque et

Archives Canada

Direction du

Patrimoine de l'édition

395 , rue Wellington

Ottawa ON K1A ON4

Canada
Your file Votre référence

ISBN: 978-0-494-93508-8

Our file Notre référence

ISBN: $978-0-494-93508-8$
NOTICE:

The author has granted a nonexclusive license allowing Library and Archives Canada to reproduce, publish, archive, preserve, conserve, communicate to the public by telecommunication or on the Internet, loan, distrbute and sell theses worldwide, for commercial or noncommercial purposes, in microform, paper, electronic and/or any other formats.

The author retains copyright ownership and moral rights in this thesis. Neither the thesis nor substantial extracts from it may be printed or otherwise reproduced without the author's permission.
AVIS:

L'auteur a accordé une licence non exclusive permettant à la Bibliothèque et Archives Canada de reproduire, publier, archiver, sauvegarder, conserver, transmettre au public par télécommunication ou par l'Internet, prêter, distribuer et vendre des thèses partout dans le monde, à des fins commerciales ou autres, sur support microforme, papier, électronique et/ou autres formats.

L'auteur conserve la propriété du droit d'auteur et des droits moraux qui protege cette thèse. $\mathrm{Ni}$ la thèse ni des extraits substantiels de celle-ci ne doivent être imprimés ou autrement reproduits sans son autorisation.
In compliance with the Canadian Privacy Act some supporting forms may have been removed from this thesis.

While these forms may be included in the document page count, their removal does not represent any loss of content from the thesis.
Conformément à la loi canadienne sur la protection de la vie privée, quelques formulaires secondaires ont été enlevés de cette thèse.

Bien que ces formulaires aient inclus dans la pagination, il n'y aura aucun contenu manquant. 


\begin{abstract}
Increasingly businesses realize the realities of the global economy, in which they must move quickly to capture revenue and market share. Rapid innovation is possible only when firms take advantage of the complementary assets of other firms and work collaboratively as a business ecosystem. While ecosystem and network theory can explain how certain platforms and firms are able to dominate their market, there is a lack of predictive ability in these tools and they require significant industry context. This paper investigates the efficacy of landscape theory as a simple and extensible model with which to understand alliance formation in a business ecosystem, focusing on how mobile platform providers and device manufacturers should align themselves to gain a dominant market share. This research reveals landscape theory to be valuable in the study of the evolution of the mobile industry and provides a basis for further study of such business ecosystems.
\end{abstract}




\section{Acknowledgements}

This thesis was a long time in the making and its completion is a triumphant moment for me personally. This journey has taught me many research and analytical skills but most importantly it has reinforced how important proper guidance and support are to any achievement of this kind.

First and foremost I would like to express my sincere gratitude to my supervisor, Dr. Michael Weiss, for his guidance, constant encouragement and most importantly, patience throughout this entire process. He has always been available to respond to my questions and queries and his invaluable suggestions have been vital to shaping this research.

I am thankful to Dr. Tony Bailetti, and Dr. Steven Muegge for their constructive feedback at various stages of the research. I would also like to thank my classmates in the TIM program for numerous pointers, tips, resources and support.

Special mention must be made of Dr. Robert Axelrod and Dr. Rahul C. Basole, who clarified various concepts and shared data from their work, which have greatly enriched this research. Their responsiveness and enthusiasm was very encouraging. Thanks also to Tor Björn Minde of Ericsson Labs for pointing me to valuable data resources on the mobile industry.

Lastly, I would like to take the opportunity to thank my family, friends and colleagues for their unconditional support throughout this journey. It has made all the difference. 


\section{Table of Contents}

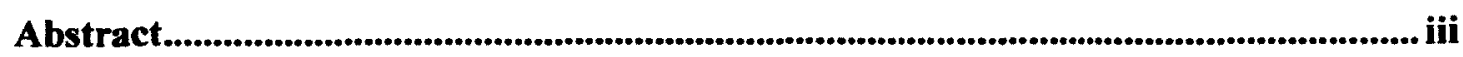

Acknowledgements ..................................................................................................... iv

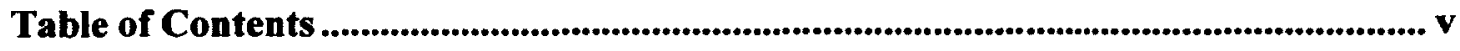

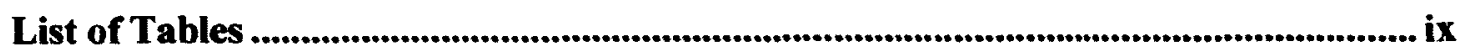

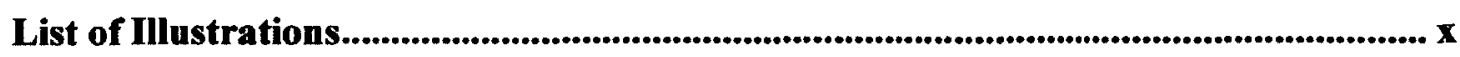

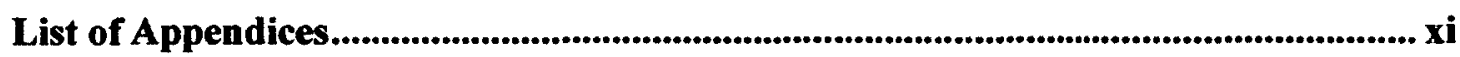

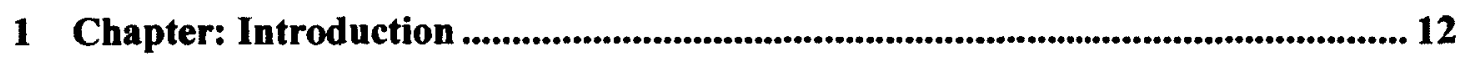

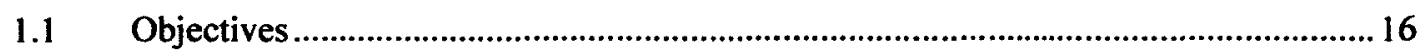

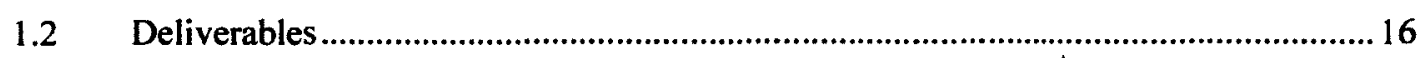

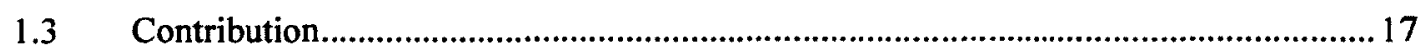

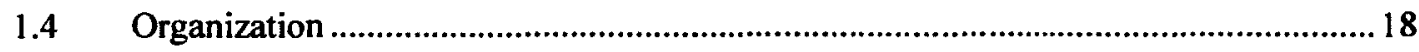

2 Chapter: Literature Review ................................................................................... 20

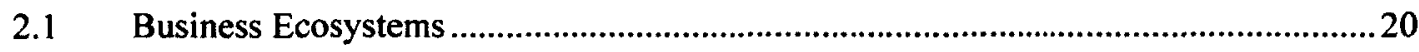

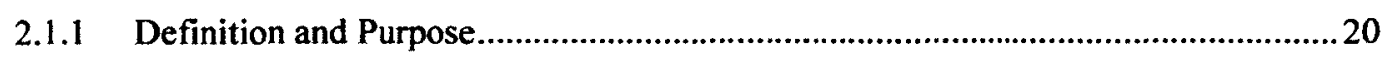

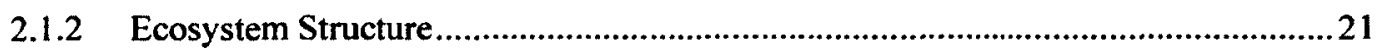

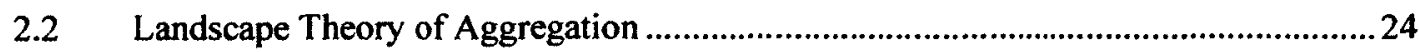

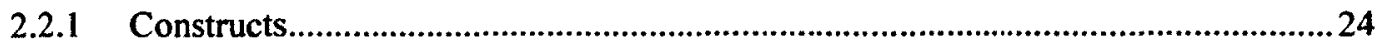

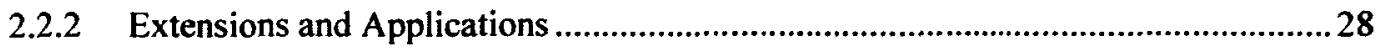

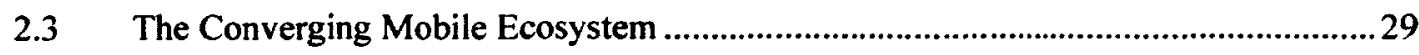

2.3.1 Mobile Industry as a Business Ecosystem .........................................................29

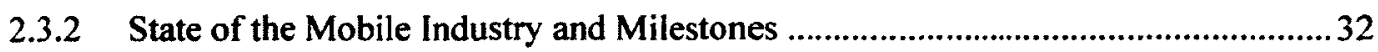

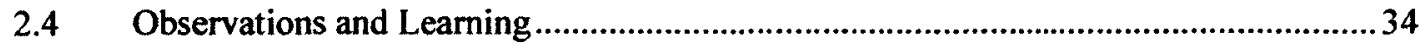

2.4.1 Mobile Industry as a Business Ecosystem ….......................................................... 34 
2.4.2 Parallels between Business Ecosystems and Landscape Theory ..............................34

2.4.3 Prior Application of Landscape Theory to Standards Setting Alliances...................35

2.4.4 Existing Analysis of the Mobile Ecosystem can help to formulate a Landscape

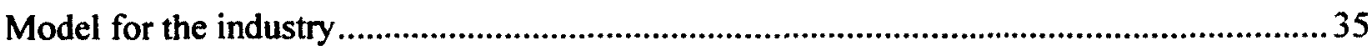

2.4.5 Limitations of Landscape Theory Model ..............................................................36

3 Chapter: Research Methodology ............................................................................ 38

3.1 Choosing firms for the Mobile Landscape Model.........................................................38

3.1.1 MPPs are keystones or hubs in the mobile ecosystem ...........................................38

3.1.2 MNOs, MDMs and MADs are the other central segments of the mobile ecosystem 38

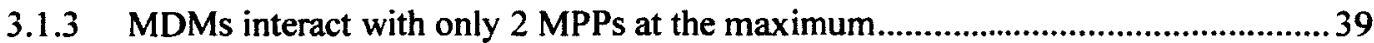

3.1.4 Only some MPPs have licensable mobile OS platforms ...........................................39

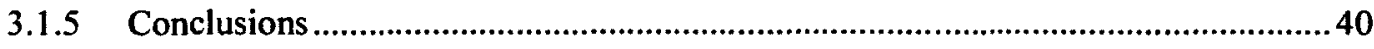

3.2 Multi Alliance Landscape Model ............................................................................ 41

3.2.1 Deconstruction of Multiple alliances to Pairwise Comparision ................................41

3.2.2 Manipulation of the Distance in existing Landscape Theory Model .......................43

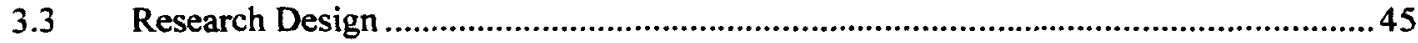

3.3.1 The Mobile Landscape Theory Model ....................................................................46

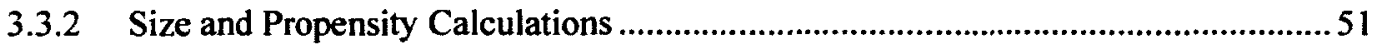

3.3.3 Example - 2006 Size and Propensity Values (2 MPPs, 5 MDMs)...........................52

3.3.4 Example - 2009 Size and Propensity Values (3 MPPs, 5 MDMs) .........................53

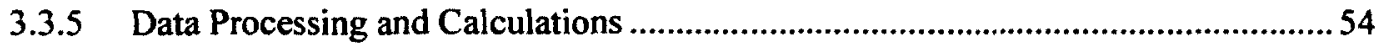

4 Chapter: Initial Results .................................................................................................. 55

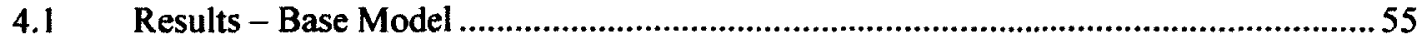

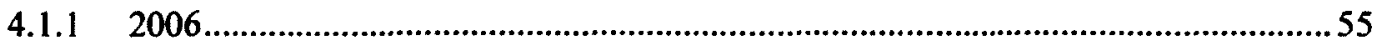

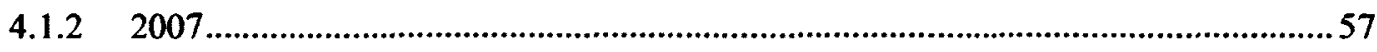




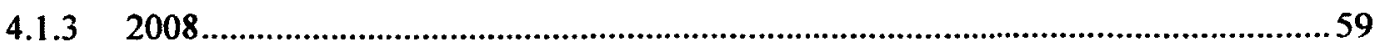

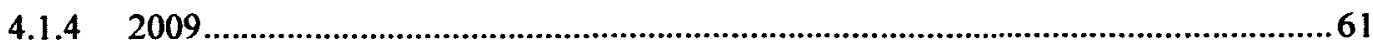

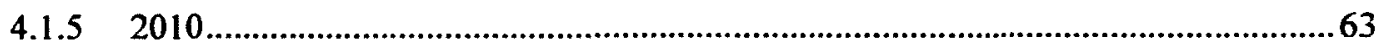

5 Chapter: Refining the Mobile Landscape Model..................................................... 66

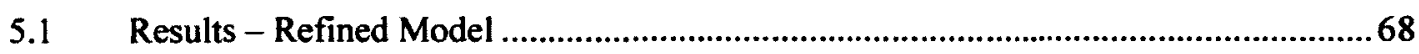

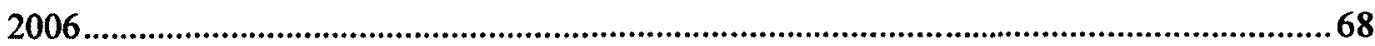

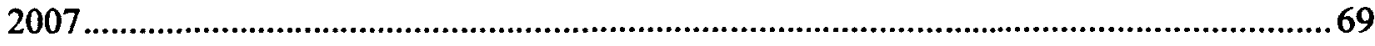

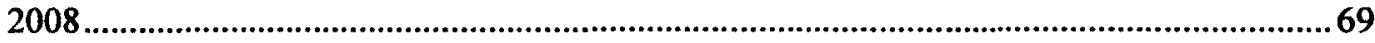

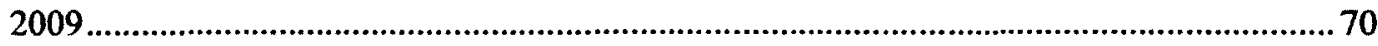

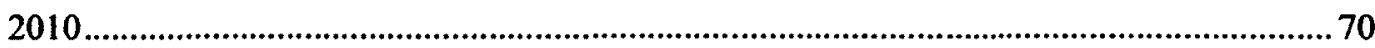

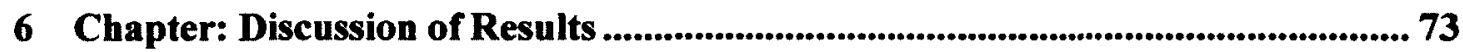

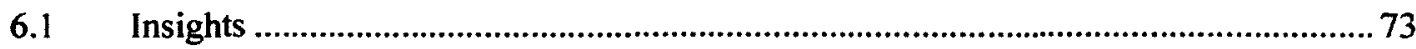

6.1.1 Basic Metrics are good indicators of alliance structure …........................................73

6.1.2 Base model yielded great insights into the MDM alliances .....................................74

6.1.3 Refining model yielded very definitive results on the alliance structure ..................74

6.1.4 Time lag doesn't affect the results of the model ....................................................74

6.1.5 Model suggests optimal decisions firms should make …......................................75

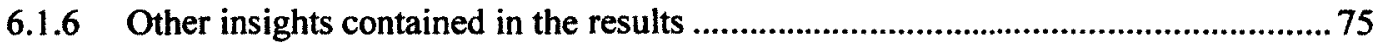

6.1.7 Disruptive innovation is difficult to model ............................................................. 76

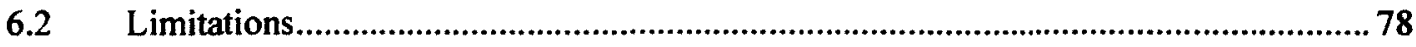

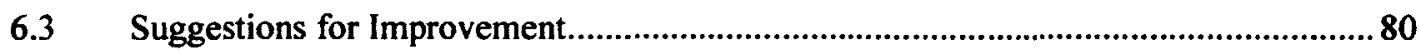

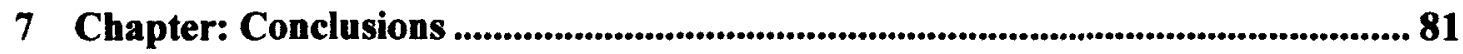

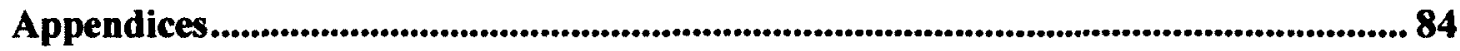

Appendix A Landscape Theory - A Primer .................................................................................. 84

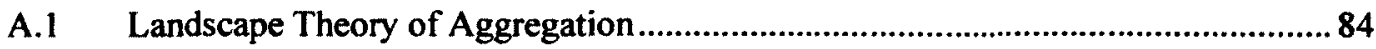




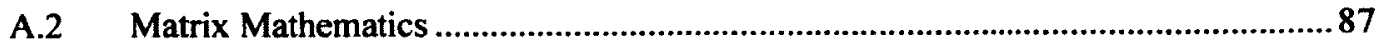

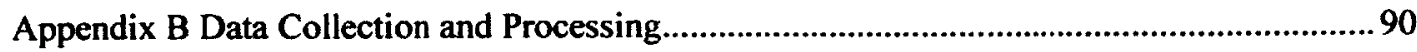

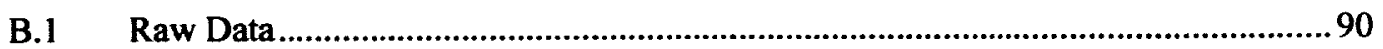

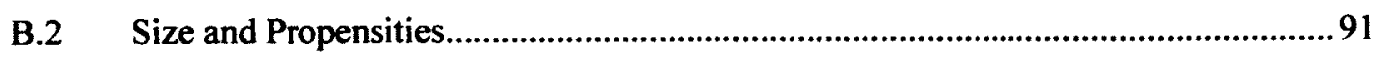

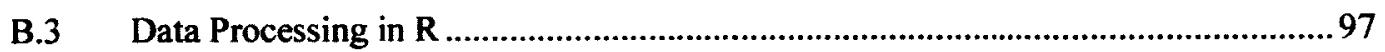

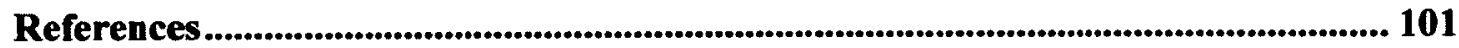




\section{List of Tables}

Table 1: Strategic Roles within a Business Ecosystem (Iansiti \& Levien, 2004)............ 23

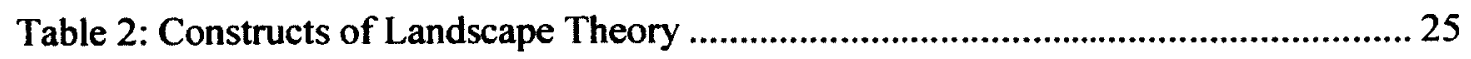

Table 3 Network Analysis Results for MNOs and MDMs (Basole \& Karla, 2011) ....... 31

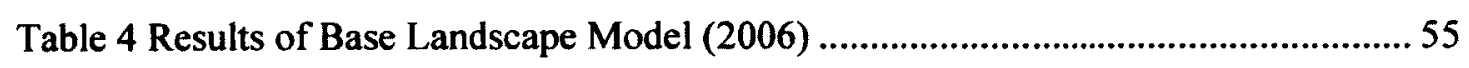

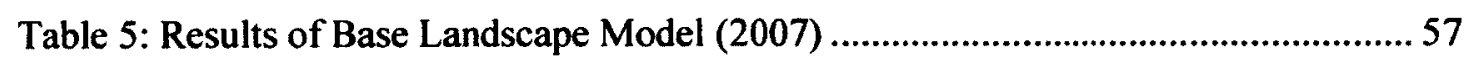

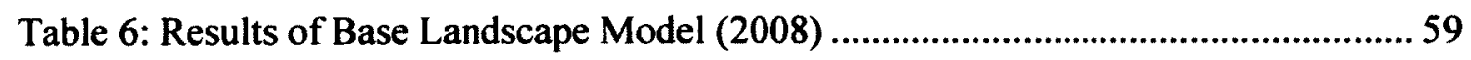

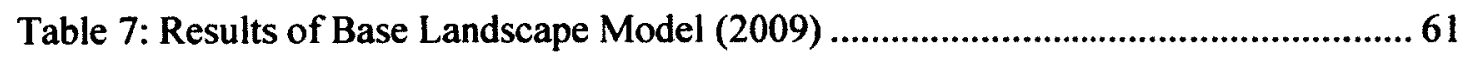

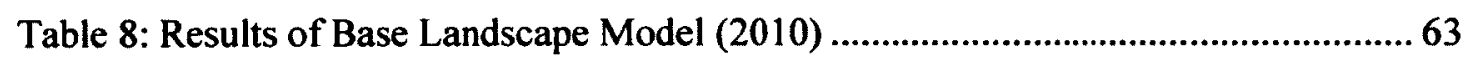




\section{List of Illustrations}

Figure 1: The Evolutionary Stages of a Business Ecosystem (Moore, 1993) ................. 22

Figure 2: Definition of Utility Function (Axelrod et. al., 1995) ....................................... 26

Figure 3: Definition of Energy Function (Axelrod et. al., 1995) ..................................... 27

Figure 4: The Food Web and Converging Mobile Ecosystem Models of the Mobile

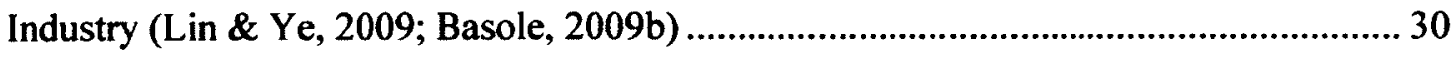

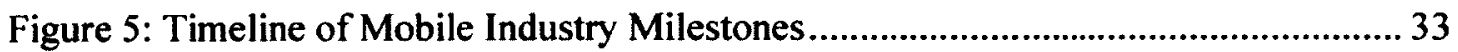

Figure 6: Sample results of Pairwise Comparison of MPPs .......................................... 43

Figure 7: Example of Distance Matrix Calculation ....................................................... 44

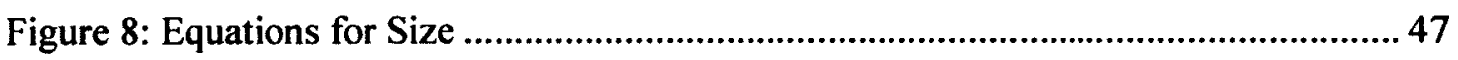

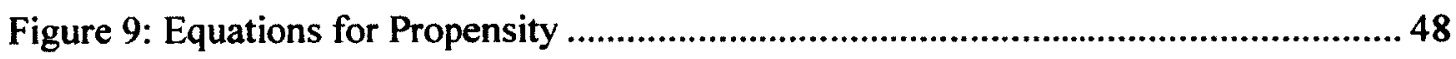

Figure 10: Visualization of Mobile Ecosystem, 2006 (Basole, 2009b) .......................... 56

Figure 11: Visualization of Mobile Ecosystem, 2007 (Basole, 2009b) ........................... 58

Figure 12: Visualization of Mobile Ecosystem, 2008 (Basole, 2009b) ...........................60 60

Figure 13: Visualization of Mobilole Ecosystem, 2009 (Basole \& Karla, 2011 ) ............. 62

Figure 14: Visualization of Mobile Ecosystem, 2010 (Basole \& Karla, 2011 ) ............... 64

Figure 15: Modified Equations for Propensity ............................................................68

Figure 16: Optimal Result from Refined Landscape Model (2006) ................................ 68

Figure 17: Configurations and corresponding Distance matrices.................................. 85

Figure 18: Example of Size, Propensity and Distance Matrices................................... 88

Figure 19: Calculation of the Utility values from Actors in the System .........................88

Figure 20: Calculation of Energy for a particular Configuration ..................................88 


\section{List of Appendices}

Appendix A Landscape Theory - A Primer....................................... 84

A.1 Landscape Theory of Aggregation......................................... 84

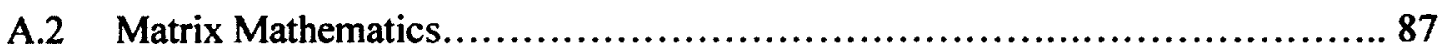

Appendix B Data Collection and Processing ..................................... 90

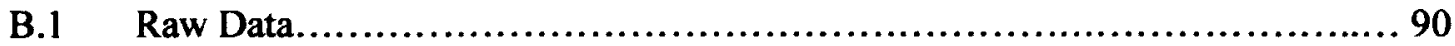

B.2 Size and Propensities.................................................... 91

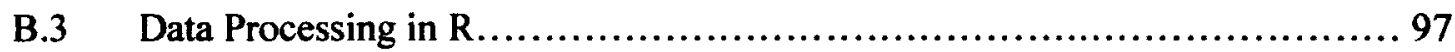




\section{Chapter: Introduction}

Increasingly businesses are realizing the realities of the global economy, in which firms must move fast to capture opportunities, revenue and market share. Rapid innovation cycles are possible today, only when firms take advantage of complementary assets of other firms and work collaboratively. Stopping to reinvent the wheel can result in firms having to play catch up later, or worse, becoming irrelevant altogether.

This business scenario applies to the mobile industry as well, where the emergence of smartphones over the past six years has resulted in the convergence of traditional and newer players into a collaborative and competitive environment, where firms need to work together to appropriate the most value out of their combined market offering as well as compete by differentiating themselves. In this new interdependent mobile world, Moore's (1993) seminal work on the structure of businesses as an ecosystem of dependent entities is perhaps the best way to characterize and explain business interactions, and the mobile business has been repeatedly studied in the research within the framework of business ecosystems theory (Gueguen \& Isckia, 2009; Basole, 2009a; Lin \& Ye, 2009).

Part of the central premise of an ecosystem is the emergence of a platform on top of which businesses can offer value-added products and services. This type of organization is also seen in the converging mobile ecosystem, where mobile operating system (OS) providers are poised to take the central role of platform providers, and serve as a link between the various traditional and newer players in the ecosystem. This central 
connective role within the industry leads to platform providers being looked at as the keystones of the converging mobile ecosystem, as it is these firms that provide the stable common asset of a mobile OS platform to which other players can link complementary products and value added services (Iansiti \& Levien, 2004). In this way, the actions of a keystone are instrumental in determining the success of every player that is connected to it, and the success of the ecosystem itself.

In order to be successful, keystones must structure their platform such that it can rapidly grow and achieve a large market share and installed base of customers i.e. become the dominant design. Keeping in mind the interconnected nature of the organizations within an ecosystem, one of the most effective ways to study this growth is using network theory.

Network theory posits that as a technology platform attracts more users, its perceived value increases, and becomes more attractive to new potential customers. This provides increasing returns as the network increases. This effect is seen time and again within the technology industry and widely used to explain the emergence of a dominant platform. In many cases, network effects of a technology are so strong that they can override its deficiencies and disadvantages over its competitors. A classic example of this is the emergence of Microsoft's Windows as the dominant PC platform over IBM and Apple.

However, network theory has some limitations. Firstly, for each example of network effects cited in the literature, there are different factors which affect why and how a 
platform gains traction and attracts users, thereby achieving the dominant status.

Deconstructing the success path often requires deep knowledge of the ecosystem around the platform and industry mechanisms. In the PC example, the Windows platform had the advantage of having a large variety of software being developed for the operating system, which increased the value of the platform as a whole and brought new users to it. To understand the network effects at play here, one needs to understand the structure of the PC ecosystem, specifically the interplay of the software application providers with the operating system provider.

A second limitation of network theory is that it is mainly a retrospective analytical tool. It has been used to explain the evolution of a platform or keystone to achieving dominance, but only after the fact. While this offers insights into what factors to consider for future success, these change from time to time and industry to industry (as mentioned above). Therefore, network theory is not as useful as a predictive device, and when it is used, detailed knowledge and data about the industry is virtually a pre-requisite

Due to these limitations, network theory does not offer us a full understanding of the converging mobile ecosystem, where the battle for the dominant platform is still in its nascent stages, with several mobile OS providers competing to achieve that status. Each of these providers is trying to attract players offering complementary assets, such as the device manufacturers and applications developers, but offer very different value propositions. As such, there is no clear winner or pre-dominant platform in this 
ecosystem yet and it would be interesting to observe how the ecosystem changes over time, until such a platform becomes clear.

What would be even more useful, especially for the firms that are looking to make an investment decision to align with one OS platform over the other, would be to be able to predict and analyze which OS they should put their investment dollars in. With the limitations that network theory poses, another approach to solving this problem would be to consider Axelrod \& Bennett's (1993) Landscape Theory of Aggregation.

Landscape theory is a framework with which Axelrod and Bennett (1993) have studied alliance formation. This theory takes a few variables related to the clout of each "actor" in the system (Size) and their tendency to ally with all other actors in the system (this is said to determine their Propensity to work together). Using the Size and Propensity measures, the optimal alliance for the actors in a system can be determined.

The theory has been widely used to predict alliances for World War 2, the airline industry, and UNIX standards setting and corroborates with the actual coalitions that were formed.

Applying this to the mobile ecosystem, we can determine which mobile OS platform the mobile device manufacturers, mobile application providers or mobile network operators, should align themselves with in order to appropriate the most value for their business.

In this way, landscape theory is a complementary tool to network theory for predicting and understanding business ecosystems and platform success. 


\subsection{Objectives}

This research aims to better understand how alliances form within a business ecosystem, specifically the converging mobile ecosystem.

In particular, this paper explores if the landscape theory model can provide an indication of what the optimal alliances between mobile platform providers (MPPs) and mobile device manufacturers (MDMs) would be. The results of the model are compared to the actual alliances formed in the mobile ecosystem, thus providing an idea of the efficacy of landscape theory in studying alliance formation within a business ecosystem.

Subsequent sections will explain how the firms in the mobile ecosystem were chosen for analysis as well as how the original landscape model was extended for use in this context.

As a result of this research, it is hoped that landscape theory is recognized as a valuable tool for the study of alliances within ecosystems and employed widely within the mobile industry and beyond.

\subsection{Deliverables}

Through this research paper, firms in the mobile industry and market research firms will have a model based on landscape theory with which to determine what strategic cooperative and competitive stances different players within the mobile ecosystem should adopt. By inputting basic parameters of company size, such as revenue and market share, 
and adding information of rivalry between firms, the model is a valuable tool that allows mobile device manufacturers to view optimal alliance structures for themselves in relation to other device manufacturers and mobile OS platform providers. Additional knowledge about the industry can be added to the model in order to increase its efficacy. In this way, the effects of previous success factors (possibly found through a study of the network effects) can be quantified and measured.

\subsection{Contribution}

The simplicity of the model in analyzing the potential payoffs from an alliance, as well as its extensibility to include a variety of factors is a valuable tool not only for mobile device manufacturers and platform providers, but also for other segments of the ecosystem in starting to analyze, predict and formulate future strategy. Through the use of the landscape model of the mobile industry, mobile market research firms, can take a further step in analyzing industry data and provide more valuable insights into which platforms will attract more complementary firms, thereby strengthening their ecosystem and achieving industry dominance.

For researchers, this paper provides the integration of landscape theory into business ecosystems research. By clearly showing the parallels between ecosystems theory and landscape theory constructs, and showing the applicability of the landscape model to the converging mobile ecosystem, it provides another framework with which to study ecosystems. Landscape theory also shows itself to be highly complementary to network 
effects in understanding ecosystems and platform success, by offering enhanced predictive capabilities.

\subsection{Organization}

This paper is organized into six chapters.

Chapter 2 provides a selective literature review of the related streams of interest, namely business ecosystems (as applied to the mobile industry) and landscape theory. This includes a discussion of the parallels between these two streams of research. Literature on the application of business ecosystems theory to the mobile phone industry is also covered. To provide a brief industry context to those readers unfamiliar with the mobile ecosystem, an overview of certain industry milestones is provided, selected for their relevance to the firms considered in the research problem and to aid in the understanding of the results.

Chapter 3 describes how the mobile landscape model was developed from the observations and lessons learned from the literature review. It explains how the landscape model was extended to handle scenarios where more than two alliances can occur. The chapter also describes the data collected and how it was used in the model.

Chapter 4 shows the predicted and optimal alliances that were obtained based on the information entered into the mobile landscape model that was developed in the previous chapter. These results are compared to the existing information and visualizations of the ecosystem that are available. The efficacy of the model and discrepancies between what the model predicts and real data are discussed. 
Chapter 5 explores possible parameters that can be used to further refine the landscape model and shows how the application of such an additional parameter to the model results in more accurate alliance predictions.

Chapter 6 summarizes the results and discusses the limitations of the research.

Chapter 7 discusses the contribution and conclusions from this research, as well as avenues for further study. 


\section{Chapter: Literature Review}

The literature on this research topic splits into two main areas - the theoretical basis consisting of business ecosystems and landscape theory of aggregation, and research on the mobile industry, particularly mobile OS platforms.

\subsection{Business Ecosystems}

The literature on business ecosystems considers the application of the biological ecosystem concept in the field of management and social sciences. This stream looks at the definition of what a business ecosystem is and its purpose, and what distinguishing properties and features it has.

\subsubsection{Definition and Purpose}

Moore (1993) initially defined the business ecosystem to mean companies that cannot be viewed as a part of a single industry but span a variety of industries. In this system, companies depend on each other to drive cycles of "reciprocal innovation", which is termed co-evolution. Co-evolution encompasses both collaborative and competitive actions between firms in the ecosystem. Iansiti and Levien (2004) further elaborate on this concept stating that ecosystems also include those collaborations between companies that fall outside of the traditional value chain roles of supply and distribution, once again indicating the broad range of business domains that a single ecosystem encompasses. However, they point out that drawing the precise boundaries of an ecosystem is an impossible task, given the complex, intertwined relationships between members. At best, they recommend that a firm closely examine its critical dependencies to determine the most important relationships it has in the ecosystem. 
Moore (2005) refines the ecosystems concept to be the third organizational structure for business, after markets and hierarchies. He further expands on the concept of coevolution by proposing that an ecosystem is a plan for how the contributions in a proposed system will be modularized, and what sorts of firms will provide which element. Hargadon (2002) agrees on this concept, describing innovation as a construction of new ideas from existing ones. From this perspective, the ecosystem is an infrastructure where the mastery of various modules by individual firms can allow easier recombination. This provides shorter learning curves, the sharing of past experiences across organizations and brings diversity to the innovation process (Weiss \& Gangadharan, 2009).

Moore (2005) also introduces two key analogies for the structure of ecosystems. The first describes the ecosystem as a landscape of contributors, with various groups encircled in interpenetrating Venn diagrams representing the many such sets within the system. In the second, Moore states that business ecosystems can be viewed as having a politics similar to a political party, where a coherent vision is possible as long as members have largely overlapping views. This is what enables successful innovation to be carried out. At the same time, complete unification in views is not desirable as it reduces the total diversity of ideas within this innovation system.

\subsubsection{Ecosystem Structure}

The second key area of research in the business ecosystem literature stream is that of the ecosystem infrastructure and its properties. 
Moore (1993) describes the business ecosystem as having stages of evolution consisting of birth, expansion, leadership and self-renewal. Figure 1 below, shows a diagram explaining the cooperative and competitive directions that need to be adopted by the firm in each stage of the evolution.
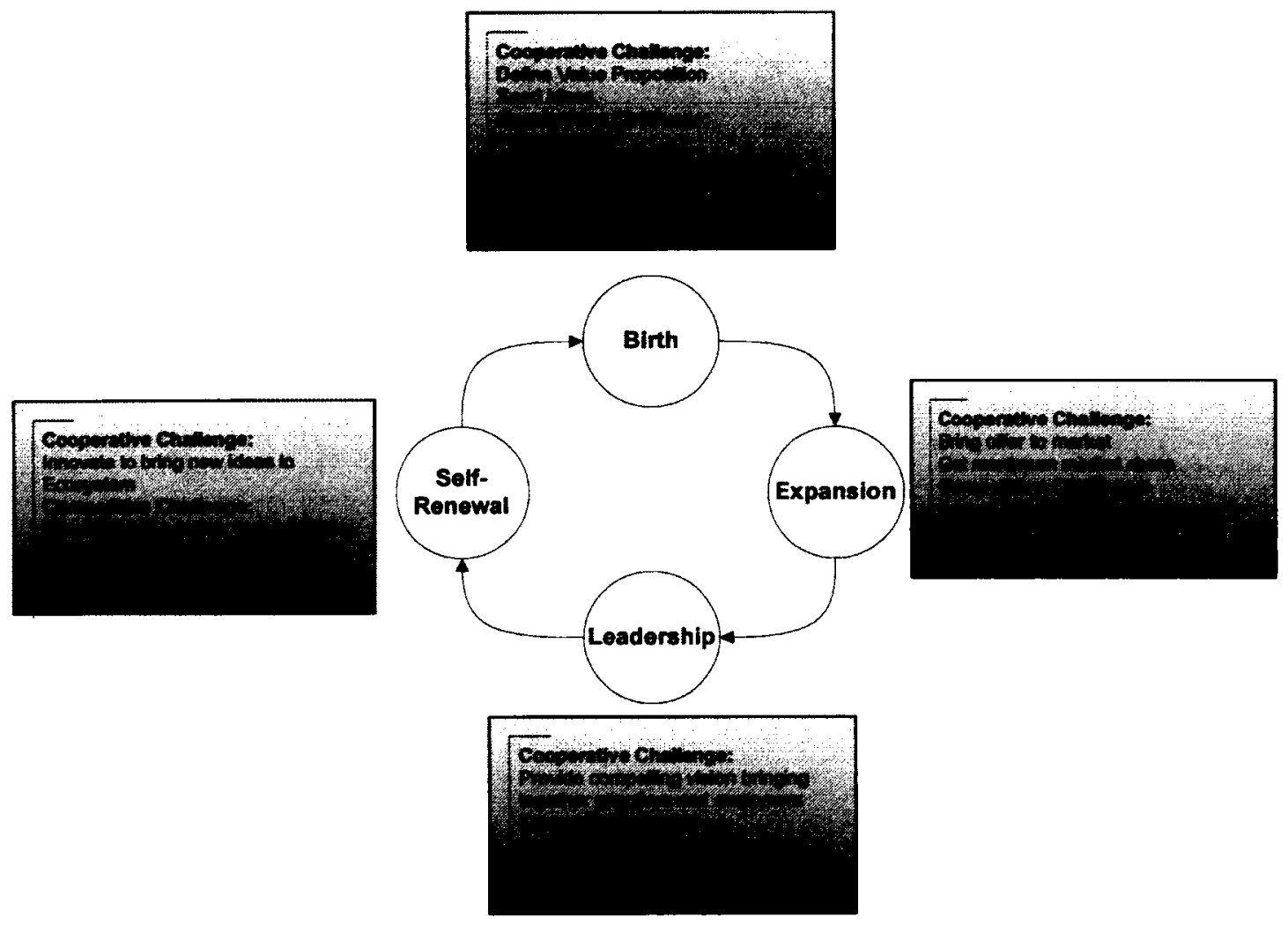

Figure 1: The Evolutionary Stages of a Business Ecosystem (Moore, 1993)

Moore (1993) mainly explores ecosystems from the perspective of companies who are looking to become what he calls "central ecological contributor". These are those firms that provide a key innovation to the ecosystem, without which other members could not survive. Other firms join to provide "genetic diversity" to the system. 
Iansiti and Levien (2004) provide a more detailed taxonomy of ecosystem members, in terms of the strategic roles they can adopt. They re-label the central ecological contributor as the keystone. The keystone aims to improve the ecosystem by providing a stable and predictable set of common assets. The keystone and other members of the ecosystem are described in Table 1. The role the firm adopts determines the strategy that it implements as part of the ecosystem.

Table 1: Strategic Roles within a Business Ecosystem (Iansiti \& Levien, 2004)

\begin{tabular}{|c|l|}
\hline Role & \multicolumn{1}{|c|}{ Characteristics } \\
\hline Keystone & $\begin{array}{l}\text { Provides a stable and predictable set of common assets } \\
\text { Assumes responsibility of connecting network } \\
\text { participants to one another }\end{array}$ \\
\hline Physical Dominator & $\begin{array}{l}\text { Integrates horizontally or vertically to directly own and } \\
\text { manage a large proportion of a network } \\
\text { Responsible for creating the value they capture }\end{array}$ \\
\hline Value Dominator & $\begin{array}{l}\text { Has little direct control over its ecosystem } \\
\text { Creates little value while extracting as much as possible }\end{array}$ \\
\hline Niche Player & $\begin{array}{l}\text { Develops specialized capabilities that differentiate it } \\
\text { from others } \\
\text { Leverages complementary resources to enhance narrow } \\
\text { domain of expertise } \\
\text { Responsible for most of the value creation and } \\
\text { innovation in the system }\end{array}$ \\
\hline
\end{tabular}

The strategy that individual firms choose as ecosystem participants directly affects the health of the ecosystem. The three critical measures of ecosystem health are productivity, robustness and niche creation (Iansiti \& Levien, 2004). Productivity refers to the system's ability to consistently transform technology and other innovation raw materials new products with lower cost. Robustness speaks to the ability of the ecosystem to survive disruptions such as those brought about by unforeseen technological change. Niche 
creation considers the capacity to increase meaningful diversity through the creation of value new functions within the ecosystem. Measures of all three are provided by Iansiti and Levien (2004).

\subsection{Landscape Theory of Aggregation}

Introduced in Axelrod et. al. (1991) and Axelrod and Bennett (1993), landscape theory of aggregation is a model that predicts how actors in a system will form alliances with others, given the choice of two possible alliances. This terminology is not to be confused

with the energy landscape model, which is used extensively in the biological and physical sciences to study protein folding and molecular behavior. The two models are related in that they both study ways in which systems can achieve their most stable state or configuration.

\subsubsection{Constructs}

There are two assumptions made by the original landscape theory (Axelrod \& Bennett, 1993). The first is that each actor has a myopic viewpoint, meaning that it can only evaluate its relationship with any one other actor at a time, independent of all the other actors in the system. The second assumption is that adjustments to coalitions take place by incremental movement of individual actors, ruling out the possibility that a suballiance may form within a coalition and then switch allegiance as a block.

The theory has three key constructs of size, propensity and distance, which are defined in Table 2. 
Table 2: Constructs of Landscape Theory

\begin{tabular}{|c|l|}
\hline Construct & \multicolumn{1}{c|}{ Definition } \\
\hline Size $\left(\mathrm{s}_{\mathrm{i}}\right)$ & A reflection of the importance of actor, $\boldsymbol{i}$, to others. \\
\hline Propensity $\left(\mathrm{p}_{\mathrm{ij}}\right)$ & $\begin{array}{l}\text { The willingness of two actors to cooperate. } \\
\text { The theory assumes that propensity is symmetric - } \mathrm{p}_{\mathrm{ij}}=\mathrm{p}_{\mathrm{ii}}\end{array}$ \\
\hline Distance $\left(\mathrm{d}_{\mathrm{ij}}\right)$ & $\begin{array}{l}\text { A measure of whether two actors are in the same alliance } \\
\text { structure or not }- \text { if the actors are in the same alliance, then } \\
\text { the distance between them is assigned to be } 0, \text { if they are in } \\
\text { different alliances, the distance is assigned to be } 1 .\end{array}$ \\
& $\begin{array}{l}\text { Distance is calculated for each possible alliance } \\
\text { configuration, given a certain number of actors, } n .\end{array}$ \\
\hline
\end{tabular}

Size is a reflection of the importance of an actor in the system. In order to form the largest alliance for itself, an actor will try to align with as many large actors as possible. The assumption here is that a larger alliance will have increased clout and collective resources to influence outcomes in their favor than a small alliance would.

Propensity is the other parameter in the model and it measures the willingness of two actors to work together. Actor I might be of a large size but if actor $J$ has a negative propensity to work with I, then J will likely try to position itself as far away from I as possible i.e. is the other alliance. Thus, even though J would like to be a part of the largest alliance, it will at the same time want to avoid being in the same alliance with actors that it has a negative propensity to cooperate with. In this way, the Size and 
Propensity influence the actors in differing ways as they try and arrange themselves into optimal alliances.

Given the definitions for Size and Propensity, it is then possible to determine the utility function, $U_{i}(A)$, for each actor, $i$, in the system, i.e. the payoff function of the actor. Utility for actor $l$ is defined as the sum of the size of each of the other actors multiplied by their propensity to cooperate with I.

$$
U_{i}(A)=\sum_{j \in A} s_{i} p_{i j}
$$

Figure 2: Definition of Utility Function (Axelrod et. al., 1995)

An alliance structure is a particular partition of all the actors in the system such that each actor is in one and only one grouping. Landscape theory is defined only for a maximum of two possible alliances within the system, with actors being a member of either one or the other, but not both.

For example, in a system with 4 actors and 2 possible groups that they can belong to, there are $2^{3}$ or 8 unique configurations for possible alliance structures. Once defined, size and propensity are independent of alliance structure. However, distance is dependent on it and will change with each configuration. For each possible configuration, a different distance matrix will be generated, as the actors will be organized in different groups each time. 
All possible configurations are iterated through to find the one in which the weighted sum of the utilities of each actor is minimized. This is called the energy of the system, $E(X)$.

$$
E(X)=\sum_{i} \sum_{j} s_{i} s_{i} p_{i j} d_{i j}(X)
$$

Figure 3: Definition of Energy Function (Axelrod et. al., 1995)

The lower the energy of a configuration, the more optimal it is as an alliance structure. This is achieved by, as far as possible, placing firms that have negative propensities to work together in opposing alliances (so that the distance between them is 1 as opposed to 0 ) as this will result in lower energy values (negative real numbers). The effect is multiplied if the firms are both also large in size.

By mapping the energy values for each possible configuration, an energy "landscape" can be generated, which is where the name of the theory comes from. The configuration or configurations which compute to the lowest energy value are the ones that the landscape model puts forth as the "optimal" arrangement of the actors into alliances. Axelrod et. al. (1995), show that these optimal alliances correspond to the local minima of the energy function. The local minima are also stated in the same paper to be the Nash equilibria solutions of the problem, with Nash equilibria being a solution concept used in game theory to find best decision a player can make given a priori knowledge of all the other players' decisions. This is a significant result since Nash equilibrium solutions mean that the player has knowledge of other players' actions, while in the landscape model no such information is known to an individual player. Thus it speaks to the power of the landscape model in being simple yet effective tool for determining optimal alliance structures. 
Local minima indicate the most viable and stable configurations, making the particular coalitions described by that configuration more likely. A further implication is that if multiple local minima occur, the one into which the system settles can depend on the history of the system i.e. what the initial configuration looks like (Axelrod et. al. 1995).

\subsubsection{Extensions and Applications}

Axelrod and Bennett (1993) first applied landscape theory to the World War Two coalitions of Allies and Axis powers and the same theory was applied in a standardsetting scenario by Axelrod et. al. (1995), who used it to show its predictive ability in what are known as the UNIX standard setting wars.

The application of the theory to the UNIX wars is carried out by deriving Size values for the 9 firms in the ecosystem from their market share and revenue information. Additionally, their propensity towards each other is measured by classifying them into close and distant rivals, where close rivals have an increased negative tendency to ally (Axelrod et. al, 1995).

Murata and Kijima (2005) extended the original landscape model by introducing dynamic and external parameters. They apply the landscape theory to the airline industry and examine alliances within the industry after introducing the external parameter of reputation to influence the actions of the actors. They do this by linking them to the marginal value that each actor brings to the alliance. 
Le Breton et. al. (2007) further strengthens the link between the landscape model and study of coalition forming games in the realm of game theory.

\subsection{The Converging Mobile Ecosystem}

Besides the theoretical basis of this research, it was important to study the current literature on the mobile industry, especially where either business ecosystems or landscape theory had already been applied. For completeness, a timeline was also compiled to show the key milestones shaping the growth and evolution of the mobile ecosystem.

\subsubsection{Mobile Industry as a Business Ecosystem}

There is significant precedent of the mobile industry being described as an ecosystem with multiple firms in a variety of value segments (Basole, 2009b; Lin and Ye, 2009; Basole and Karla, 2011; Kenney and Pon, 2011). Basole(2009a) points to the convergence occurring in the mobile industry, with traditionally separate industries such as the Internet, cable, gaming and entertainment coming to mobile devices and thus creating a race to create compelling, integrated mobile products and services, and capture a piece of the revenue streams in this lucrative new market. Basole (2009a) defines this as the converging mobile ecosystem.

Basole (2009a) and Lin and Ye (2009) both characterize the firms within the industry into different value segments. While Lin and Ye (2009) use the "food web" ecosystem 
concept to describe the roles played by various firms that show their links to the end-user or customer, Basole uses two main categories - current segments and emerging segments to define the segments to which the firms of the converging mobile ecosystem belong to. Both segmentations are shown below in Figure 1, with the left hand side showing Lin and Ye's (2009) model and the right hand side showing Basole's model of the converging mobile ecosystem, with the light grey circles indicating current segments and dark grey circles depicting emerging segments.
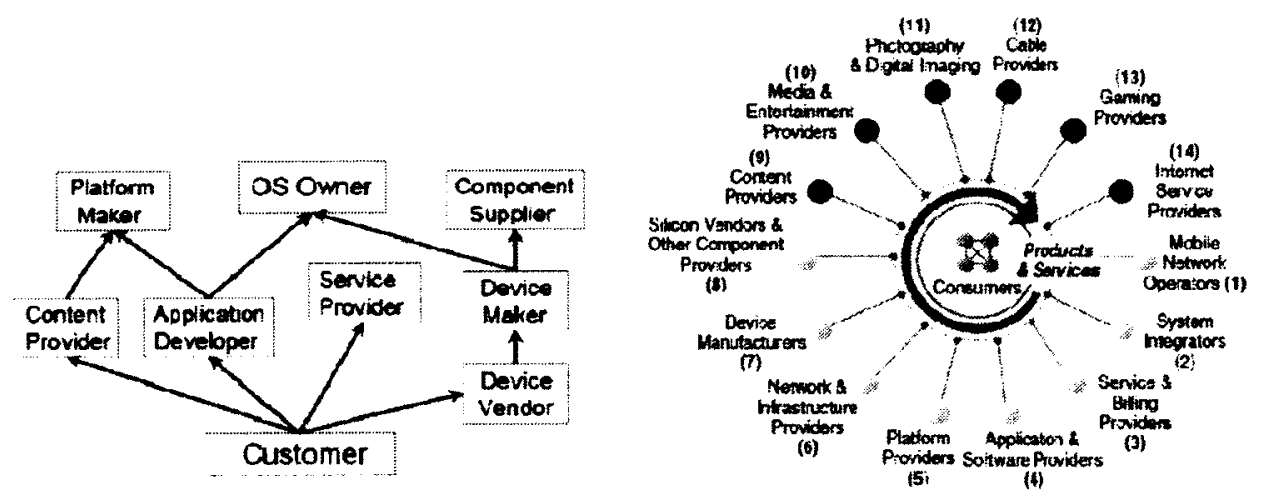

Figure 4: The Food Web and Converging Mobile Ecosystem Models of the Mobile Industry (Lin \& Ye, 2009; Basole, 2009b)

Of the segments that Basole (2009a, 2009b) identifies, he names four of them as the key players in the mobile ecosystem - Mobile Platform Providers (MPP), Mobile Device Manufacturers (MDMs), Mobile Network Operators (MNOs) and Mobile Application Developers (MADs).

Of these, MPPs are repeatedly described in the literature (Basole, 2009b; Kenney, 2011) to be playing the role of broker in the mobile ecosystem, and due to their role in 
providing the technology platform for other value segments, drive other value chains in the mobile space. With each mobile platform acting as a hub, several platform- centered ecosystems are forming within the overall ecosystem. A visualization of ecosystem over time shows this very phenomenon (Basole, 2009b).

There are also extensive studies on the technological capabilities of the major mobile OS platforms currently, namely, Symbian, Android, Windows Mobile and iOS. Some papers (Godwin-Jones, 2008; Ghandewar \& Sheikh, 2010) even compare the mobile OS platforms head to head across various categories, including portability, connectivity and kernel size.

In additional network analysis carried out by Basole and Karla (2011) (shown in Table 3), MNOs are shown to be interacting with an increasing number of MPPs over time, with interactions with 2.5 platforms per MNO in 2006 up to 4.5 in 2010 . In the same time period, MDMs are tending to interact with 1 to 2 MPPs, with the mean degree metric being between 1.1 and 1.8 platforms per MDM.

Table 3 Network Analysis Results for MNOs and MDMs (Basole \& Karla, 2011)

\begin{tabular}{|c|c|c|c|c|c|}
\hline & 2006 & 2007 & 2008 & 2009 & 2010 \\
\hline \multicolumn{6}{|c|}{ Mobule Netwrork Uperator } \\
\hline \multirow[t]{2}{*}{ - Mean Degrec (S.D.) } & 2.412 & $2.794^{* * *}$ & $3.588^{*+*}$ & $4.176^{++*}$ & $4.500^{*+*}$ \\
\hline & $(0.701)$ & $(0.946)$ & $(1.076)$ & $(1.314)$ & $(1.187)$ \\
\hline$-\min / \max$ & $1 / 4$ & $1 / 5$ & $1 / 6$ & $1 / 7$ & $2 / 7$ \\
\hline \multicolumn{6}{|c|}{ Mobile Device Manufacturers } \\
\hline \multirow[t]{2}{*}{ - Mean Degree (S.D.) } & 1.100 & $1.455^{*}$ & $1.652^{* *}$ & 1.577 & $1.714^{* *}$ \\
\hline & $(0.308)$ & $(0.963)$ & $(0.982)$ & $(0.945)$ & $(0.976)$ \\
\hline$-\min / \max$ & $1 / 2$ & $1 / 4$ & $1 / 4$ & $1 / 4$ & $1 / 4$ \\
\hline
\end{tabular}


There is significant research in the mobile application development space, with the main highlights being studies on how MPPs can attract MADs to their app stores (Lee et. al., 2010), as well as how networks effects and overcrowding affect innovation by the MADs (Boudreau, 2011).

\subsubsection{State of the Mobile Industry and Milestones}

For better understanding and to aid the discussions of the results of the research, a description of selected milestones for the mobile industry over a period from 1998 to 2012 are shown below. 


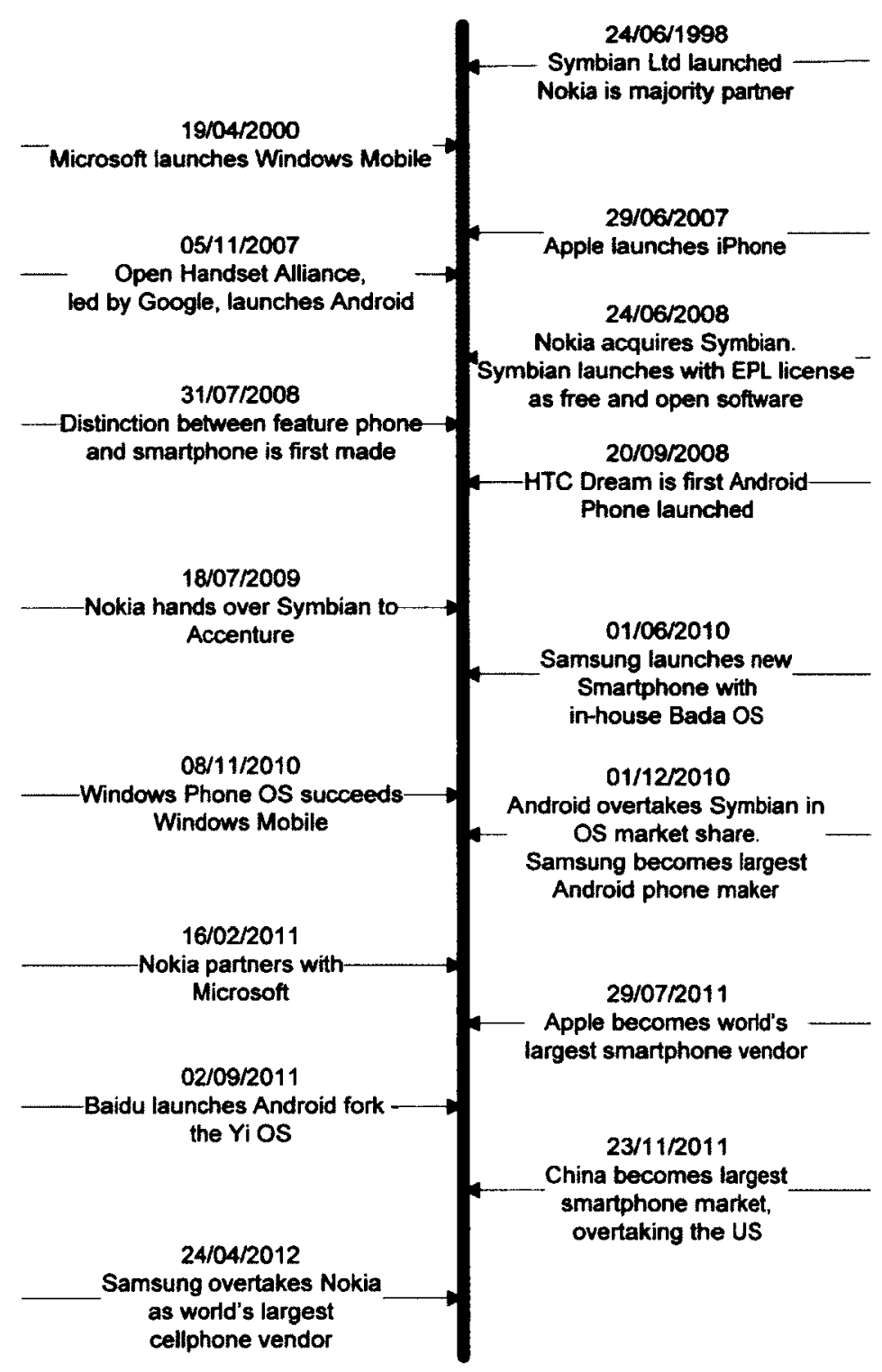

Figure 5: Timeline of Mobile Industry Milestones 


\subsection{Observations and Learning}

The main lessons learned from the literature review are summarized below.

\subsubsection{Mobile Industry as a Business Ecosystem}

The mobile industry can be viewed as a business ecosystem, which is characterized as an alliance of firms seeking ways to gain sustainable competitive advantage by collaborating with each other to obtain the benefits of recombinant innovation.

While there are some high level ideas about ecosystems, their properties, infrastructure and purpose, there is little in the way of empirical research on ecosystems and it is difficult to operationalize the extensive theoretical studies on the topic.

A review of the business ecosystem literature shows that there is a lack of research on how an ecosystem member would strategically choose allies and form alliances.

\subsubsection{Parallels between Business Ecosystems and Landscape Theory}

Given the indications in Moore's (2005) paper that alliances in an ecosystem are much like the maneuverings of members of a political coalition, an interesting parallel is drawn to the landscape theory of aggregation,(which was initially used as a model to study World War Two political alliances) as a framework with which to examine these coalitions.

Landscape theory gives constructs, such as size and propensity, which, when defined to reflect the industry in question, can lead to greater predictive and analytical capability 
about possible coalition formations. This may help explain the current and future state of the converging mobile ecosystem.

\subsubsection{Prior Application of Landscape Theory to Standards Setting Alliances}

The application of landscape theory to the Unix Wars in Axelrod et. al (1995) is especially interesting as it showed the applicability of the landscape model to an industry where standards are used as platforms upon which industry members create value added services and products.

This industry structure is common across the mobile infrastructure business (with standards such as GSM, CDMA and LTE), the Internet (standards include HTML, various social media platforms, content delivery platforms etc.), and the mobile handset industry (where the literature shows that mobile OS platforms are becoming the standard upon which other firms innovate).

This gives further increases the expectation that landscape theory can be used to model the mobile industry as successfully as was done in the Unix Wars case and provides a precedent on how to operationalize model constructs such as size and propensity.

\subsubsection{Existing Analysis of the Mobile Ecosystem can help to formulate a}

\section{Landscape Model for the industry}

Existing visualization and network analysis of the mobile ecosystem offers insights into which value segments to consider to begin building a landscape model for the mobile industry. 
Firstly, in the visualization, MPPs emerge as the key hub around which the ecosystem is beginning to structure itself. Secondly, the central segments of the converging mobile ecosystem seem to be MNOs, MADs and MDMs.

MPPs

Thirdly, the network analysis shows that MDMs will tend to ally with 1 to 2 MPPs at most, which can be attributed to the fact that they will face higher development complexity and costs for each additional mobile operating system (OS) they choose to use. Depending on the mobile OS chosen, there can be associated development costs to customize the OS, and offer MDM specific applications, or licensing costs that the MDM has to bear for each phone they launch with a particular OS platform.

Mobile OS selection decisions have less bearing on MNOs, as these firms would like the most variety of phone offerings for their customers in order to appeal to different market segments and gain as large a subscriber base as possible

Although not discussed in Basole's research, it can be speculated that MADs will act like MNOs and offer their application software on as many platforms as possible in order to reach a wider customer base. This is possible due to the lower development and startup costs offered by most of the leading MPPs, through providing rich APIs, integrated development environments (IDEs) and developer support forums for their mobile OS platforms (Boudreau, 2011).

\subsubsection{Limitations of Landscape Theory Model}


Some limitations in the theory are apparent, the chief one being that the model is designed to deal with a maximum of two alliances at a time. In the study of mobile ecosystem thus far, it is clear that there are multiple alliances that are possible, especially with the advent of the new wave of mobile OS platforms like iOS and Android. A strategy to incorporate these multiple alliances into the model would need to be developed. 


\section{Chapter: Research Methodology}

The research methodology requires combining the learning on landscape theory and the converging mobile ecosystem from the literature review to develop and operationalize the landscape theory model for the mobile industry. This involves a discussion as to which actors are considered in the model, how alliances between them are defined and the practical aspects of the research design, including how the data was gathered and processed.

\subsection{Choosing firms for the Mobile Landscape Model}

At this point, it will be helpful to restate some key observations from the literature review that are used to determine the actors or firms to be studied with the mobile landscape model, and thus define the scope of the research.

\subsubsection{MPPs are keystones or hubs in the mobile ecosystem}

Firstly, the visual representations of the mobile ecosystem over 2006-2010 (Basole, 2011) and the description of ecosystem keystones in the literature both point to Mobile Platform Providers (MPPs) as the likely hubs in the converged mobile ecosystem going forward. It is the MPPs that provide the key element (mobile OS platform) in the value chain that is used by other firms to derive revenue, whether it is network operators, device manufacturers or any of a variety of content developers and distributors. Thus, in a landscape model, MPPs are likely to be the firms around which alliance structures form.

\subsubsection{MNOs, MDMs and MADs are the other central segments of the mobile} ecosystem 
Besides the MPPs, Mobile Device Manufacturers (MDMs), Mobile Network Operators (MNOs) and Mobile Application Developers (MADs) are the other three important segments in the converging mobile ecosystem (Basole and Karla, 2011). While MDMs and MNOs have traditionally been important segments of the ecosystem, MADs are a new segment, brought to the forefront by the emergence of application-based software development for smartphones.

\subsubsection{MDMs interact with only 2 MPPs at the maximum}

Based on the network analysis carried out by Basole (2011) (shown in Table 4 of the last chapter), MNOs interact with an increasing number of MPPs over time, while MDMs are tied to just 1 to 2 MPPs, with the mean degree metric being between 1.1 and 1.8 platforms. It can be concluded from this that MDMs will be more concerned with making the right choice for MPP than the other two major segments of the converging mobile ecosystem, the MNOs and MADs, since there are significant costs associated with mobile OS platform adoption.

Thus, MDMs are best suited to be included in the landscape model, since it is designed to show preference for one alliance over another i.e. a firm cannot be a member of two different alliances (in this case, we are modeling it such that each MPP will be a hub around which an alliance will form).

\subsubsection{Only some MPPs have licensable mobile OS platforms}

Another critical differentiating point in how MNOs and MADs adopt Mobile OS platforms as compared to MDMs is that of the different MPP platforms that exist in the ecosystem, only some can be used by MDMs on their own handsets. For example, Apple and Research In Motion both produce mobile OS platforms, the iOS and Blackberry OS 
respectively. However, these platforms are proprietary and only used in the companies' own products. As such, they are not potential platforms that can be adopted by MDMs. However, MNOs and MADs can still choose to sell these phones or develop applications for these platforms respectively.

Therefore, of the mobile OS platforms that are available in the ecosystem, only some can be licensed to be used by MDMs. Thus, in the landscape model, only those MPPs that are licensable are considered, since MDMs cannot adopt or ally with closed mobile OS platforms such as iOS or Blackberry OS.

\subsubsection{Conclusions}

Given the above observations about the converging mobile ecosystem, only MDMs and licensable MPPs are considered in the mobile landscape model.

Since MNOs and MADs are likely to adopt many if not all MPPs for use in due course, it is of more value to study how MDMs will go about choosing the mobile OS platforms that it will use in its mobile phones. Thus our model only considers licensable MPPs and MDMs and their relations in the mobile ecosystem i.e. which MPP will an MDM pick to form an alliance with.

MPPs are considered to be the hubs around which alliances will form and they have a strong tendency to compete with each other. As such, there will be as many alliances formed as there are MPPs. For example, if there are 3 MPPs in the model, then 3 alliance groups will be defined, each centered around a MPP. All the MDMs are then free to ally with the MPP and other MDMs with which they can achieve the lowest energy i.e. the most stable configuration. 
Since the landscape model will ensure that an MDM is only paired with one MPP at any time, if the reality is that an MDM does pick two or more MPPs, then the model should return the one it uses the most i.e. in more of its phones.

\subsection{Multi Alliance Landscape Model}

Given the multiple mobile OS options for an MDM, there would need to be a way to predict the alliances for multiple platforms. The landscape model, as it is described in the literature, is designed to allow all the actors to choose one from at most two possible alliances. Since each mobile OS platform is modeled as a separate alliance option, and there are more than 2 mobile OS choices for MDMs in some cases, application of the model to the mobile ecosystem would require an appropriate extension to the basic landscape theory model so that the firms can choose one from multiple possible alliances. Two possibilities as to how multiple alliances could be studied via landscape theory are described in the section below.

\subsubsection{Deconstruction of Multiple alliances to Pairwise Comparison}

The first was to deconstruct the multiple alliance problem into the pairwise consideration of all the MPPs against each other. Therefore, if there are three MPPs considered Symbian, Microsoft and Google, then the original 2 alliance landscape model would be used to do a pair by pair analysis of how the MDMs will ally.

This approach is tricky because once the pairwise alliances are determined, it is difficult to combine the results to obtain the final three alliances. For example, in a system where there are 5 players, 3 MPPs (A, B and C) and 2 MDMs (D and E), there will be three pairwise comparisons carried out: $A$ against $B, A$ against $C$ and $B$ against $C$ (D and $E$ will 
be part of all three models). Figure 5 shows an example of the results that can obtained when taking this approach.

Comparison 1

$A$ and $B$ :

Alliance $1 \quad$ Alliance 2

A B Energy: -100

E D

Comparison 2

$A$ and $C$ :

Alliance $1 \quad$ Alliance 2

A C Energy: -200

D

E

Comparison 3

$B$ and $C$ :

Alliance 1

B

Alliance 2

Energy: -150

E

C

D 
Figure 6: Sample results of Pairwise Comparison of MPPs

From the Figure above, it is hard to conclusively determine what the alliance structures will be once all three alliance possibilities (A, B and C) are considered. One can argue, that since the energy of the $A$ and $C$ comparison (Comparison 2) is the lowest (Energy is -200 ), that it is the most stable configuration (i.e. A aligns with $D$ and $C$ aligns with D). However, this does not account for how B affects the system, with Comparison 1 suggesting that the addition of $\mathrm{B}$ will result in $\mathrm{E}$ aligning with $\mathrm{A}$, while Comparison 3 suggests that it will result in $E$ aligning with $B$.

This simple scenario shows that it is possible to have inconclusive final results by taking this approach to modeling multiple alliances.

\subsubsection{Manipulation of the Distance in existing Landscape Theory Model}

Another approach to solving the problem of modeling multiple alliances in landscape theory is to consider how distance is defined in the theory. As shown in Table 2, distance is defined as 0 if two firms are in the same alliance and as 1 if they are in differing alliances. This definition can be extended to 3 or more alliances by defining distance as 0 if two firms are in the same alliance and as 1 if they are in any other alliance than the same one. However, this approach significantly complicates the automation of mathematical calculations, since 3 alliances mean upto $3^{(n-1)}$ different configuration scenarios, given $\mathbf{n}$ firms in the system.

Similarly, for $\mathrm{x}$ alliances, upto $\mathrm{x}^{(\mathrm{n}-1)}$ configurations must be considered and the corresponding energy values for each calculated.

An example of how the distance matrix is determined is shown in the Figure below. 

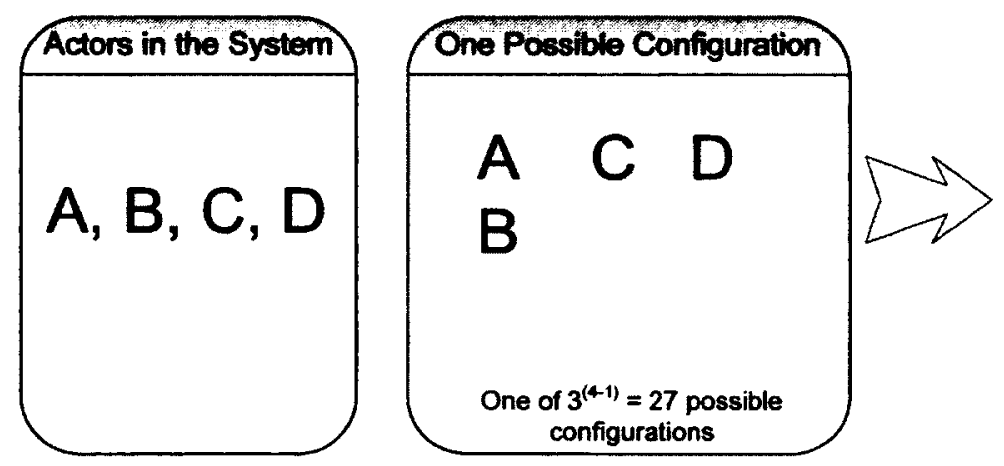

Distance Matrix

A $B$ C C D

A $0 \begin{array}{llll}0 & 0 & 1 & 1\end{array}$

$\begin{array}{lllll}B & 0 & 0 & 1 & 1\end{array}$

C 111001

D 111110

Figure 7: Example of Distance Matrix Calculation

The figure shows how the distance matrix is calculated if there are 4 actors in the system, and they are arranged in a certain configuration. Since $\mathrm{A}$ and $\mathrm{B}$ are in the same alliance, the distance between them would be 0 . They would have a distance of 1 from $C$ and $D$, as they belong to different alliances. Similarly, the distance of A, B and D from C is 1 , since they all belong to different alliances. The result is a $4 \times 4$ distance matrix for each configuration (for 4 actors, there are 27 possible configurations, or arrangements of actors into 3 alliances).

In email consultation with Dr. Axelrod, we agreed that this second approach was cleaner and more attractive in that it considered all alliances simultaneously. The automation complexities were solved by using matrix mathematics. How the automation was carried out is described in the Appendix.

The above decisions (in section 3.1 and 3.2) helped to narrow the research problem down to how MDMs will go about aligning themselves with MPPs to form alliances. 


\subsection{Research Design}

As discussed above, the unit of analysis of this research was a MDM determining which MPP to adopt by using the landscape theory model, appropriately operationalized for the converging mobile ecosystem. The complete description of the model is given in subsequent sections.

With the model year to year data from the period from 2006 to 2010 was used to determine what the optimal alliance structures for each year would have been. The results from the model were compared to the visualization data for the same 5 year period given in Basole and Karla's research (2011) and other data gathered from Internet sources for verification.

In each year period, a list of the MDMs was gathered based on those who have a significant share of the market. A $1 \%$ or greater share was considered to be a significant share of the total mobile market. This information is available through internet data and market research firms such as Gartner.

A list of MPPs was gathered from Basole's visualizations and market share data, again available through internet data from Gartner. Only those MPPs that had licensable operating systems were considered. The type of licensing model the MPP employed was not considered, and ranged from an open source license to a per use royalty-based license. As such, Apple's iOS, although popular with MNOs and MADs, will not be a 
valid mobile OS platform to consider for MDMs as it is not available for use outside of Apple's own products.

\subsubsection{The Mobile Landscape Theory Model}

Once the sample set (list of MDMs and MPPs) is complete, the next step was to operationalize the various constructs of landscape theory. The theoretical foundation and equations given in Axelrod \& Bennett (1995) were used as a basis for this research. The formation of Unix Standards alliances discussed in that paper and our attempt to find the mobile OS platform standards that will be used in the mobile ecosystem are similar in nature, which makes this theoretical foundation a good one on which to base a model for the mobile industry.

For operationalization, the individual firm size and the propensity of all the firms in the system to work with each other had to defined and measured. As was shown in Table 3, size is a reflection of the importance of a firm to others in the ecosystem. In the Unix Standards setting case (Axelrod \& Bennett, 1995), size is measured through the market share and revenue, which would be appropriate measures in the case of the mobile ecosystem members as well, as they provide a good indication of influence of the various firms. Market share is a common indicator of firm performance in the mobile industry, making it an easy metric to obtain as well as an important indicator of firm "clout" in the ecosystem. Similarly, revenue of a MPPs mobile division indicates the investment capability that a firm may have to launch and establish a mobile OS platform through providing the software development kits (SDKs), support forums and application stores or marketplaces to fully develop the value network around the platform. 
In the case of MDMs, operating profit is a good indicator of the money a firm has to reinvest into the $R \& D$ activities of developing new mobile phones, which will also involve choosing the mobile OS platform for the handsets. These size measures are described in the equations below

$$
\begin{gathered}
\text { Size } \left._{\text {MPP }}=1 / 2 \text { (Market Share }\right)+1 / 2(\text { Revenue }) \\
\text { Size }_{\text {MDM }}=1 / 2(\text { Market Share })+1 / 2(\text { Operating Profit })
\end{gathered}
$$

Figure 8: Equations for Size

Equal weightage was given to the market share and revenue (in the case of MPPs) or operating profit (in the case of MDMs) to come up with a Size value for each of the MPPs and MDMs which are part of the study. The Size value will change from year to year as the revenue, operating profit and market share data vary annually.

The data points for the market share, revenue and operating profit were obtained from the annual reports and tax filings of the publicly listed companies that were studied. If the companies were not public, then press releases and news stories were used to gather the information.

For propensity, the model in Axelrod \& Bennett (1995) also fit the research sample nicely. In that paper, UNIX companies were divided into specialist and generalist firms based on their product and service portfolios. Axelrod and Bennett speculated that firms falling in the generalist category would have an increased negative propensity to working with other generalists, since they would compete across many products and services (defined as close rivals), while a specialist and generalist would have a less negative 
propensity to work (defined as distant rivals) Similarly, there are two firm segments in the research problem we are considering - MPPs and MDMs, which have differing roles in the ecosystem. The propensity for MPPs and MDMs (distant rivals) to work together would be less negative while MPP-MPP and MDM-MDM (close rivals) propensity would be more negative. Another way to look at this would be to view MPPs to be close rivals of other MPPs, and MDMs to be close rivals of other MDMs. MPPs and MDMs would be distant rivals of each other. This is directly related to whether a firm will adopt a competitive or cooperative stance towards another. In the case of an MPP, we make the simple observation that it will most likely compete with another MPP, which has a directly competing market offer, while cooperating with a MDM, which has a complementary asset which, if it uses their mobile OS platform, would help strengthen their ecosystem. The reverse case would apply to a MDM, i.e. it will cooperate with a MPP while competing with another MDM. In the case of the Unix wars, the propensity of distant rivals was modeled as $[1-\alpha]$, while close rivals were modeled as $[1-(\alpha+\beta)]$.The equations below show this information as a formula:

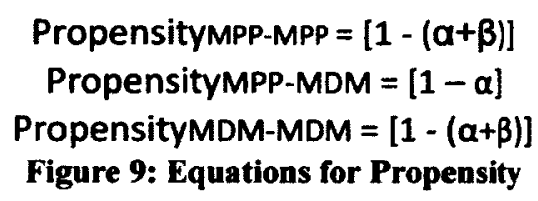

In the equations above, we use the value of 1 for alpha and beta, as it is used in Axelrod et. al (1995). Substituting the alpha and beta values into the propensity equations above, would give the following basic propensity values:

$$
\begin{aligned}
& \text { PropensityMPP-MPP }=[1-(\alpha+\beta)]=[1-(1+1)]=-1 \\
& \text { PropensityMPP-MDM }=[1-\alpha]=[1-1]=0
\end{aligned}
$$




$$
\text { PropensityMDM-MDM }=[1-(\alpha+\beta)]=[1-(1+1)]=-1
$$

In order to use the existing landscape model for more than 2 possible alliance choices, as discussed in section 3.2.2., (i.e. where a MDM can choose between multiple OS platforms such as Windows Phone, Android and Symbian, for example), we define distance as follows:

$$
\begin{aligned}
\text { Distance, } D_{i j}= & \{0, \text { if } i \text { and } j \text { are in the same alliance } \\
& \{1, \text { if } i \text { and } j \text { are not in the same } \\
& \text { alliance }
\end{aligned}
$$

To measure distance, we use the same algorithm as described in section 3.2 .2 , with distance 0 denoting two firms in the same alliance and distance 1 denoting that they are in different alliances. Note that if there are three MPP groups, say Group 0, Group 1 and Group 2, and Firm A is in the Group 0 alliance and Firm B is not, then the distance between Firms A and B is 1. It does not matter whether Firm B is in Group 1 or Group 2 in order to calculate the distance between A and B.

Propensity values were easy to generate as the companies just had to be classified as a MPP or MDM. This information was known but was also verified by reviewing the product offerings of the various companies. This information was readily available on the Internet through the company website and sites such as Wikipedia.

In order to do the calculations, an automation script was written in R (language and environment for data manipulation and calculation) that converted inputted size and propensity values into $I x n$ and $n x n$ matrices respectively, with $n$ being the number of 
firms being considered in the model. The script then generated all the possible alliance structures given $\mathbf{n}$ firms, and the distance matrix was generated. With the size, propensity and distance matrices, we can start to input them to the equations given to calculate the Utility and Energy (per firm and total for the system) per possible alliance structure. The script also determines where the lowest total energy of the system occurs, and gives the corresponding alliance structures. These are the local minima for system.

Note that the Utility and Energy equations for the total system are given as follows:

$$
U_{i}(A)=\sum_{j \in A} s_{i} p_{i j}
$$

where $P_{i j}$ is the propensity of two firms to ally, is $[1-(a)]$ when $i$ and $j$ are distant rivals and $[1-(\alpha+\beta)]$ when $i$ and $j$ are close rivals. These propensities are symmetric i.e. firms I and $J$ have an equal tendency to want to compete/cooperate with each other. The Energy function is the summation of all the Utility functions, weighted by the firm's size.

$$
E(X)=\sum_{i} \sum_{j} s_{i} s_{i} p_{i j} d_{i j}(X)
$$

As mentioned above, $d_{i j}(X)=0$ when $i$ and $j$ are in the same alliance and 1 when they are in different alliances.

If there are $n$ firms (MPPs and MDMs) being considered in the sample, where there are at most two MPPs, then there would be $2^{(n-1)}$ unique alliance structures possible in which to arrange $\mathrm{n}$ firms in 2 groups (alliances). These would all have to be iterated through to find those that give the lowest energy value for the system. The configurations with the 
lowest energy are the optimal, or most stable. Similarly, in the case of three MPPs, there

would be $3^{(n-1)}$ configurations to be considered, and so forth.

A copy of the $R$ script and description of the matrix operations carried out are in the Appendix.

\subsubsection{Size and Propensity Calculations}

For each year, the data from the previous year is used to determine the size and propensity values. For example, for 2006 , data up to the last day of 2005 is used. This would allow us to observe if the previous year's data can provide some predictive power on the future direction a firm will take with respect to choosing its' alliances.

For 2006, 2007,2008, and 2009, the MDMs (those holding at least 1\% market share) considered were Nokia Corporation, Motorola Inc., Samsung Group, Sony Ericsson Mobile Communications AB and LG Electronics. Symbian and Microsoft were the MPPs involved, offering the Symbian operating system and Windows Mobile respectively until 2008, when Google introduced the Android operating system. (Note that Android is reflected only from 2009 onwards in the landscape model, since only data from the previous year is used)

For 2010, two new MDMs that held $1 \%$ or more market share in 2009 - ZTE Corporation and Huawei Technology Co Ltd - were added to the model.

Size and propensity values were calculated based on the equations given in Figures 6 and 7 above. The calculated size and propensities for 2006 (2 MPPs, 5 MDMs) and 2009 (3 
MPPs, 5 MDMs) are shown below. The rest of the size and propensity tables for years 2007 through 2010 are available in the Appendix.

\subsubsection{Example - 2006 Size and Propensity Values (2 MPPs, 5 MDMs)}

Size:

\begin{tabular}{|l|r|r|l|r|}
\hline 2006 & $\begin{array}{l}\text { Revenue } \\
\text { (millions } \\
\text { USD) }\end{array}$ & $\begin{array}{l}\text { Market } \\
\text { Share }\end{array}$ & $\begin{array}{l}\text { Operating } \\
\text { Profit } \\
\text { (millions } \\
\text { USD) }\end{array}$ & \multicolumn{1}{|l|}{ Size } \\
\hline & & & & \\
\hline Microsoft & 262 & 17 & & 139.5 \\
\hline Symbian & 114.8 & 51 & & 82.9 \\
\hline Linux & & 23 & & \\
\hline Nokia & & 34.9 & 5502 & 2768.45 \\
\hline Motorola & & 21.8 & 4605 & 2313.4 \\
\hline Samsung & & 11.7 & 2426 & 1218.85 \\
\hline Sony Ericsson & 6.3 & 607 & 306.65 \\
\hline LG & & 6.8 & 441 & 223.9 \\
\hline
\end{tabular}

Size for MPPs is calculated by taking into account revenue and market share, while for

MDMs it was calculated using market share and operating profit. In cases where the company reported its revenue or operating profit in currency other than US dollars, the appropriate conversion was applied (using the closing exchange rate for the year before).

The propensity table below is derived directly from the equations in Figure 7.

Propensity:

\begin{tabular}{|l|r|r|r|r|r|r|r|}
\hline 2006 & MS & Symbian & \multicolumn{1}{l|}{ Nokia } & Motorola & Samsung & \multicolumn{1}{l|}{ Sony E } & \multicolumn{1}{l|}{ G } \\
\hline MS & 0 & -1 & 0 & 0 & 0 & 0 & 0 \\
\hline Symbian & -1 & 0 & 0 & 0 & 0 & 0 & 0 \\
\hline Nokia & 0 & 0 & 0 & -1 & -1 & -1 & -1 \\
\hline Motorola & 0 & 0 & -1 & 0 & -1 & -1 & -1 \\
\hline Samsung & 0 & 0 & -1 & -1 & 0 & -1 & -1 \\
\hline Sony E & 0 & 0 & -1 & -1 & -1 & 0 & -1 \\
\hline
\end{tabular}




\begin{tabular}{|l|l|l|l|l|l|l|l|}
\hline LG & 0 & 0 & -1 & -1 & -1 & -1 & 0 \\
\hline
\end{tabular}

\subsubsection{Example - 2009 Size and Propensity Values (3 MPPs, 5 MDMs)}

Size:

\begin{tabular}{|l|r|r|r|r|}
\hline 2009 & \multicolumn{1}{|l|}{ Rev } & \multicolumn{1}{l|}{$\begin{array}{l}\text { Market } \\
\text { Share }\end{array}$} & $\begin{array}{l}\text { Operating } \\
\text { Profit }\end{array}$ & \multicolumn{1}{l|}{ Size } \\
\hline Microsoft & 8140 & 11.8 & & 4075.9 \\
\hline Symbian & 291.7 & 52.4 & & 172.05 \\
\hline Nokia & & 38.6 & 6718 & 3378.3 \\
\hline Motorola & & 8.7 & 0 & 4.35 \\
\hline Samsung & & 16.3 & 2190 & 1103.15 \\
\hline Sony & & & & \\
Ericsson & & 7.6 & 124.5 & 66.05 \\
\hline LG & & 8.4 & 1136 & 572.2 \\
\hline Google & 4227 & 0.5 & & 2113.75 \\
\hline
\end{tabular}

Note that for 2009, a new MPP was added - Google. The size calculations are all carried out in the same way. Note that in the case of an operating loss instead of profit for a

MDM, the operating profit was entered as 0 (see Motorola example above).

The propensity table was generated using the Figure 7 propensity equations.

Propensity:

\begin{tabular}{|l|r|r|r|r|r|r|r|r|}
\hline & MS & Symbian & Google & Nokia & Motorola & Samsung & \multicolumn{1}{l|}{ Sony E } & \multicolumn{1}{l|}{ LG } \\
\hline MS & 0 & -1 & -1 & 0 & 0 & 0 & 0 & 0 \\
\hline Symbian & -1 & 0 & -1 & 0 & 0 & 0 & 0 & 0 \\
\hline Google & -1 & -1 & 0 & 0 & 0 & 0 & 0 & 0 \\
\hline Nokia & 0 & 0 & 0 & 0 & -1 & -1 & -1 & -1 \\
\hline Motorola & 0 & 0 & 0 & -1 & 0 & -1 & -1 & -1 \\
\hline Samsung & 0 & 0 & 0 & -1 & -1 & 0 & -1 & -1 \\
\hline SonyE & 0 & 0 & 0 & -1 & -1 & -1 & 0 & -1 \\
\hline LG & 0 & 0 & 0 & -1 & -1 & -1 & -1 & 0 \\
\hline
\end{tabular}




\subsubsection{Data Processing and Calculations}

Data processing and calculation was done using $R$, a software environment for data manipulation and calculation. Version 2.13.1 of the software was used, with an additional package (sfsmisc) loaded to provide access to additional functions. Further details and the $\mathbf{R}$ script can be found in the Appendix. 


\section{Chapter: Initial Results}

The results were obtained from the mobile landscape models for 2006 through 2010 by applying the size and propensity values calculated to the utility and energy functions that are shown in previous sections. Based on the model, the alliance structures that result in the lowest energy are the optimal configurations. These are described in the tables below and compared to the visualizations generated by Basole (2009b) and Basole and Karla (2011) to see what the predictive value of the landscape model results is. The year by year visualizations from Basole and Karla (2011) are shown in the figures below with the relevant firms magnified to show their relationships.

\subsection{Results - Base Model}

\subsubsection{6}

Table 4 Results of Base Landscape Model (2006)

\begin{tabular}{|llll|}
\hline Configuration 1 & & Configuration 2 & \\
Microsoft & Symbian & Microsoft & Symbian \\
Nokia & Motorola & Motorola & Nokia \\
Sony Ericsson & Samsung & Samsung & Sony Ericsson \\
LG & & & LG \\
\hline
\end{tabular}




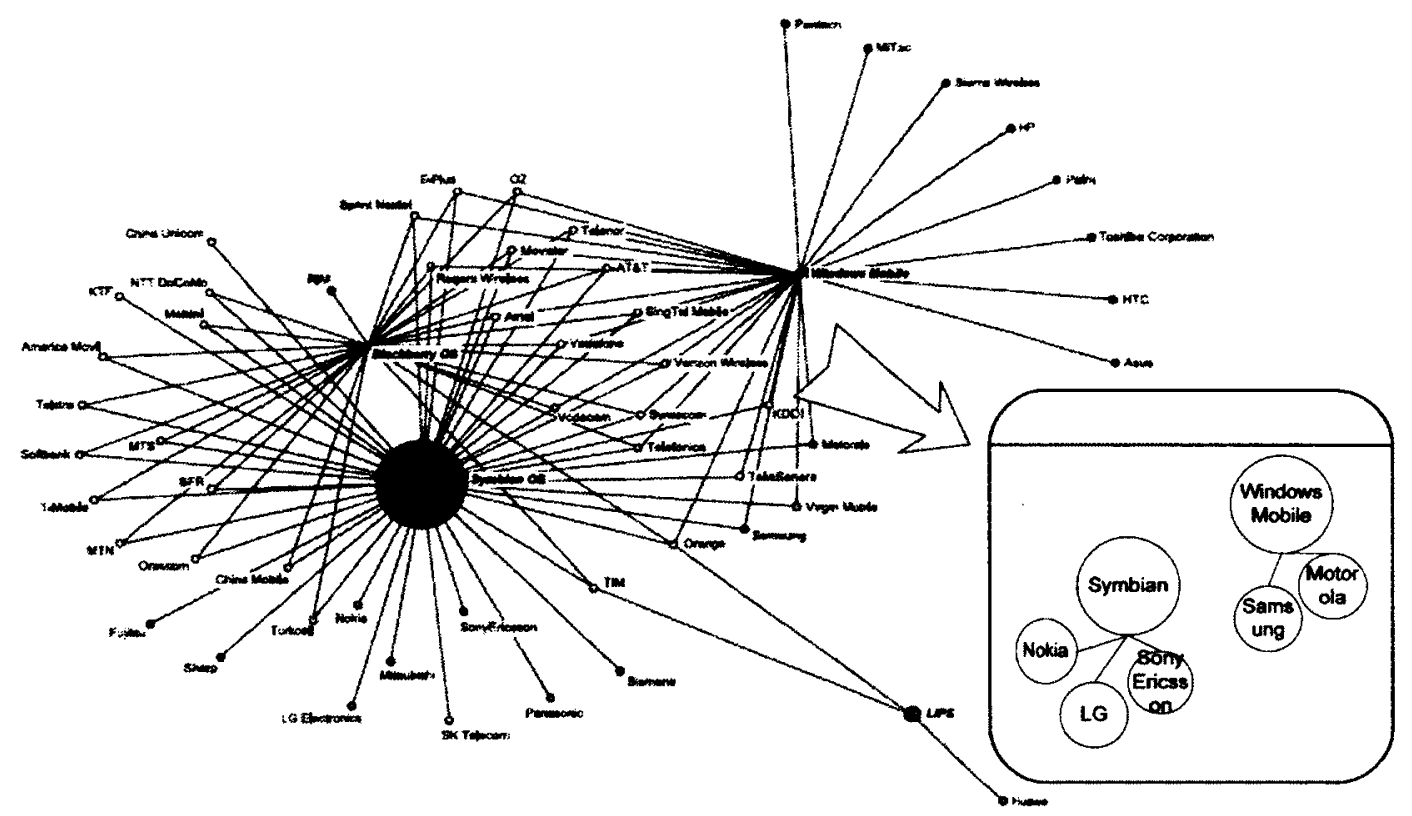

Figure 10: Visualization of Mobile Ecosystem, 2006 (Basole, 2009b)

For 2006, two possible optimal alliance structures resulted from the landscape model. Of these, we can make the following observations. Motorola and Samsung, the number two and three largest MDMs by market share will have a tendency to position themselves in an alliance separate from Nokia, the number one MDM. Smaller players such as Sony Ericsson and LG will tend to align themselves with the largest alliance i.e. the one that has the largest size. In this case, that would mean that they align with Nokia, which is the single biggest MDM in terms of market share and operating profits in 2006, even though they have a negative propensity to align with a competing MDM.

While clearly showing their affinity or distancing from the other MDMs in the system, neither of the MDM firms show a preference for one MPP or the other, This is due to the 
fact that MPP-MDM propensity is assigned a value of 0 (or neutral) in the model, resulting in zero contributed energy to the system. Therefore there is no impact to overall energy even if MDM firms align with a different MPP.

With basic knowledge of the mobile ecosystem, it is clear that Nokia will align with Symbian and not Microsoft (Nokia being a stakeholder in the Symbian Foundation). This means that Configuration 2 is the more viable out of the two results.

When comparing Configuration 2 (shown in Table 4) to the 2006 visualization of the ecosystem by Basole (2009b), we can see that the results of the model fit the actual structure of the ecosystem quite well. Nokia, Sony Ericsson and LG are in the Symbian alliance, while Motorola and Samsung have greater ties to the Windows Mobile platform. Note that in the visualization, Motorola and Samsung also maintain ties to the Symbian platform However, the algorithm used to generate the visualization assigns meaning to the distance between the MDMs and MPPs, with Motorola and Samsung both being spatially drawn closer to Windows Mobile than Symbian. This indicates a greater "pull" or closeness to the Windows Mobile platform than Symbian for both these companies. Thus, Configuration 2 is a close representation of the actual 2006 alliance structures.

\subsubsection{7}

Table 5: Results of Base Landscape Model (2007)

\begin{tabular}{llll}
\hline Configuration 1 & & Configuration 2 & \\
Microsoft & Symbian & Microsoft & Symbian \\
Nokia & Motorola & Motorola & Nokia \\
LG & Samsung & Samsung & LG \\
& Sony Ericsson & Sony Ericsson & \\
\hline
\end{tabular}


In applying the landscape model to the year 2007 , two optimal configurations resulted.

Once again, Motorola and Samsung are placed in a rival alliance to Nokia, with Sony Ericsson joining them. LG still maintains ties to Nokia, still the largest MDM in that time period.

As mentioned in 4.1.1, Nokia will partner with Symbian as it is a stakeholder in the Symbian Foundation. Thus, Configuration 2 is the more likely result.

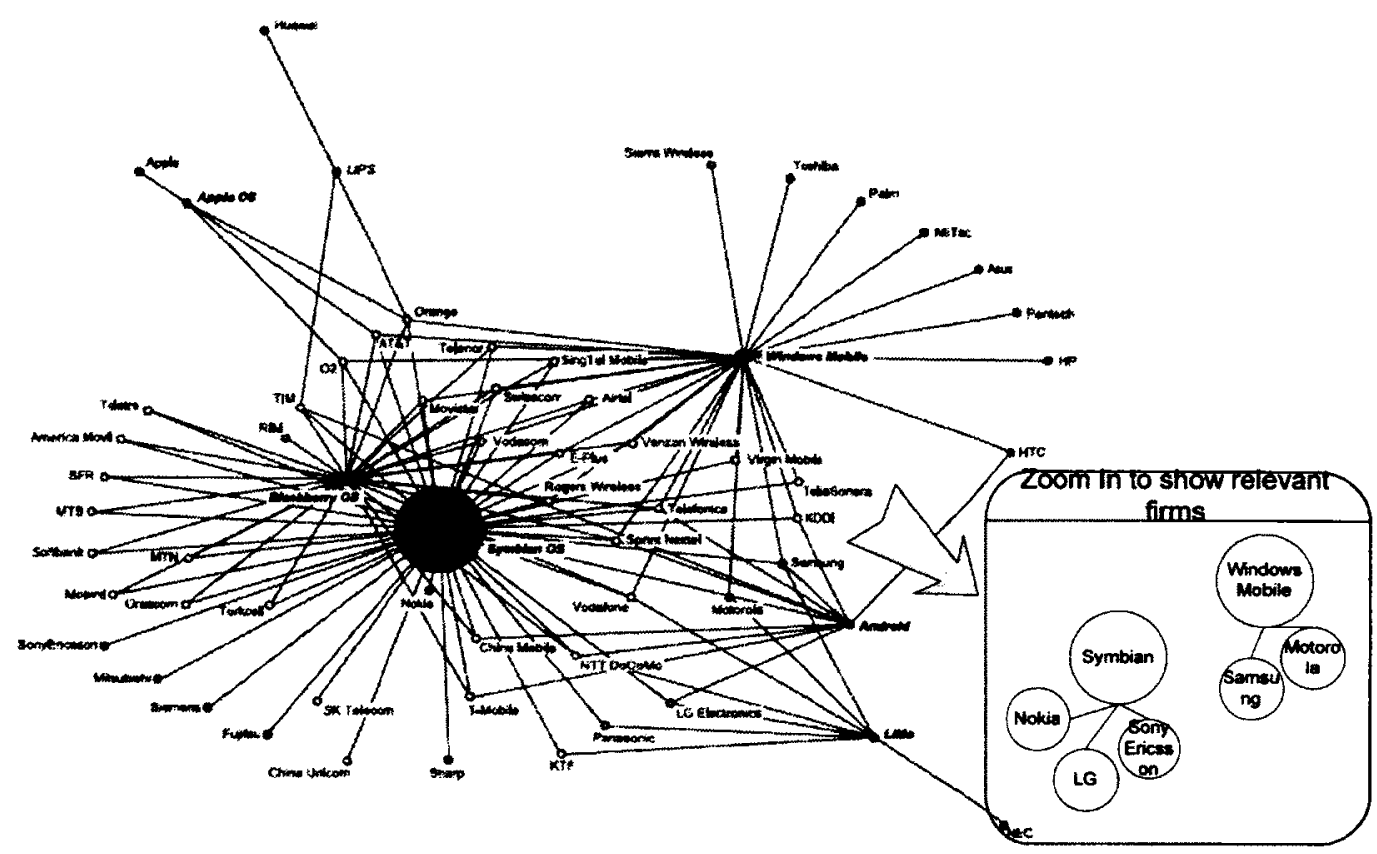

Figure 11: Visualization of Mobile Ecosystem, 2007 (Basole, 2009b)

When comparing this result to Basole's visualization, given in Figure 11, there is a single discrepancy, which is the grouping of Sony Ericsson with Windows Mobile instead of Symbian. Given knowledge of the future loss of market share and revenue for Sony Ericsson that occurs post 2008, it could be said that the real results from the 2007 visualization are in fact not the ideal alliance structures and that Sony Ericsson should 
have made the decision at this stage, to pick the other alliance or hedge bets on multiple mobile OS platforms as Motorola and Samsung did.

\subsubsection{8}

Table 6: Results of Base Landscape Model (2008)

\begin{tabular}{|llll|}
\hline Configuration 1 & & Configuration 2 & \\
Microsoft & Symbian & Microsoft & Symbian \\
Nokia & Motorola & Motorola & Nokia \\
& Samsung & Samsung & \\
& Sony Ericsson & Sony Ericsson & \\
& LG & LG & \\
\hline
\end{tabular}


For 2008, once again, Configuration 2 is a closer representation of the mobile ecosystem compared to Configuration1. We can see that the alliance structures remain similar to those seen in 2007. In this year, LG has also defected to the alliance of Samsung, Sony Ericsson and Motorola.

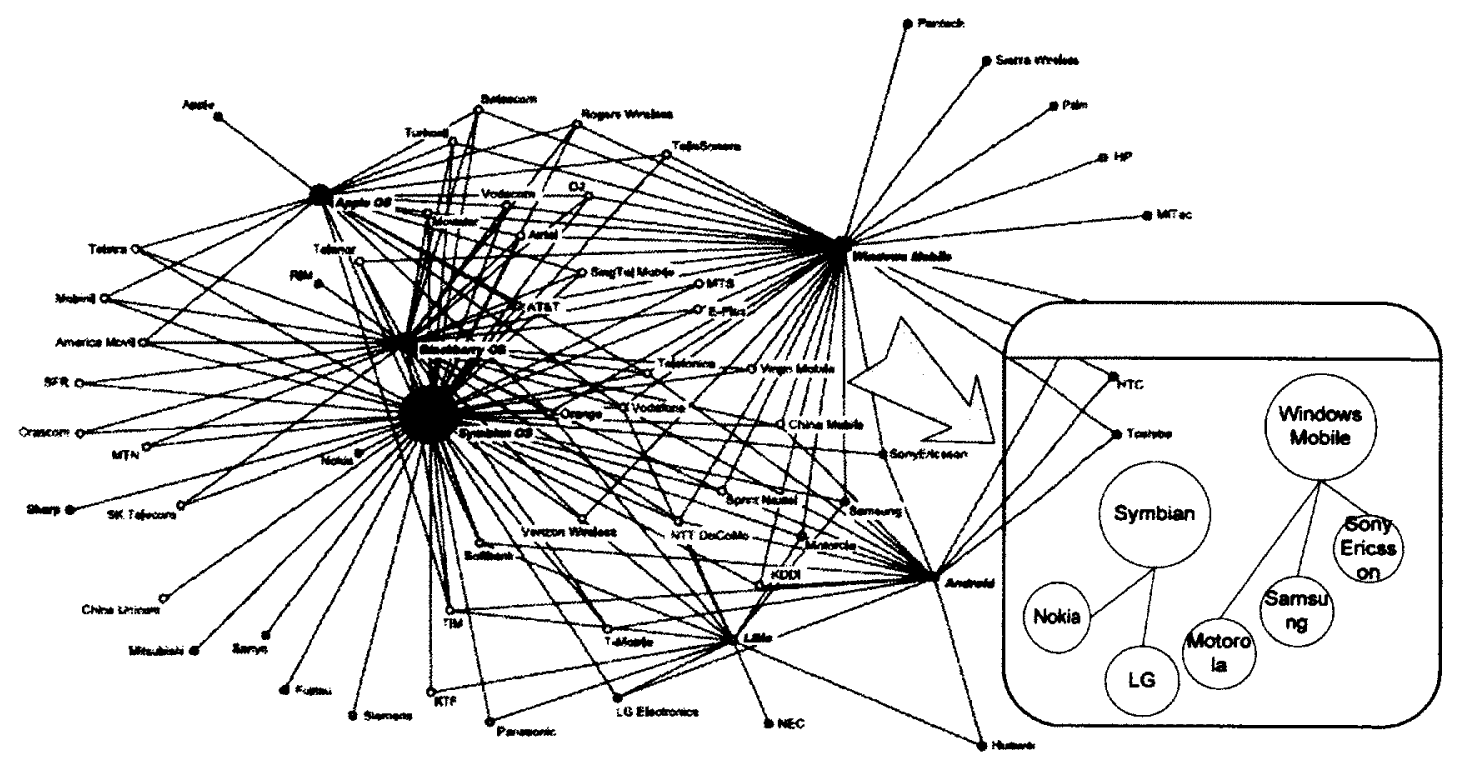

Figure 12: Visualization of Mobile Ecosystem, 2008 (Basole, 2009b)

This alignment is verified by Basole's 2008 network visualization (see Figure 12), where, although Motorola, Samsung, Sony Ericsson still have ties to the Symbian platform, their spatial distance from the platform indicates that the ties are not as strong as those to Windows Mobile. One discrepancy is that LG does not have any ties to Windows Mobile, rather moving to adopt Android and LiMo while maintaining its Symbian ties. From the visualization, we can already see the emergence of Android as a competing mobile OS platform and that these MDMs are already forming ties to it. However, since our 2008 
results are solely based on data from 2007 , Android does not figure in them since the first commercial version of the operating system was only available in 2008 .

\subsubsection{9}

Table 7: Results of Base Landscape Model (2009)

\begin{tabular}{|llllll|}
\hline $\begin{array}{l}\text { Configuration 1 } \\
\text { Microsoft } \\
\text { Nokia }\end{array}$ & $\begin{array}{l}\text { Symbian } \\
\text { Motorola }\end{array}$ & $\begin{array}{l}\text { Google } \\
\text { Samsung }\end{array}$ & $\begin{array}{l}\text { Configuration 4 } \\
\text { Microsoft } \\
\text { Samsung }\end{array}$ & $\begin{array}{l}\text { Symbian } \\
\text { Nokia }\end{array}$ & $\begin{array}{l}\text { Google } \\
\text { Motorola } \\
\text { Sony } \\
\text { Ericsson } \\
\text { LG }\end{array}$ \\
$\begin{array}{l}\text { Sony Ericsson } \\
\text { LG }\end{array}$ & & & & \\
$\begin{array}{l}\text { Microsoft } \\
\text { Nokia }\end{array}$ & Symbian & Google & Microsoft & Symbian & Google \\
& Samsung & Motorola & Motorola & Samsung & Nokia \\
Configuration 3 & & Sony Ericsson & Sony Ericsson & & \\
$\begin{array}{l}\text { Microsoft } \\
\text { Motorola }\end{array}$ & LG & LG & Configuration 6 & & Symbian \\
Sony Ericsson & Nokia & Google & Microsoft & Soogle \\
LG & & Samsung & Samsung & Motorola & Sokia \\
\hline
\end{tabular}

For 2009 , the landscape model returned 6 possible configurations. What is clear is that there are three groups of MDMs that are formed, but because of the lack of positive or negative propensity of any MDM to a single MPP (note that the propensity of all MDMs to MPPs is modeled as 0 or neutral), all the possible permutations of mobile OS platform with the three MDM alliances are returned as optimal alliance structures.

Again, as with the previous year's results, the MDMs create definite alliances, with Motorola, Sony Ericsson and LG partnering with each other, while Nokia and Samsung each choose different MPPs to ally with. The closest representation of the mobile ecosystem is Nokia pairing with Symbian and Motorola, Sony Ericsson and LG joining 
the Android platform. This leaves Samsung to partner with Microsoft on the Windows Mobile platform (Configuration 4).

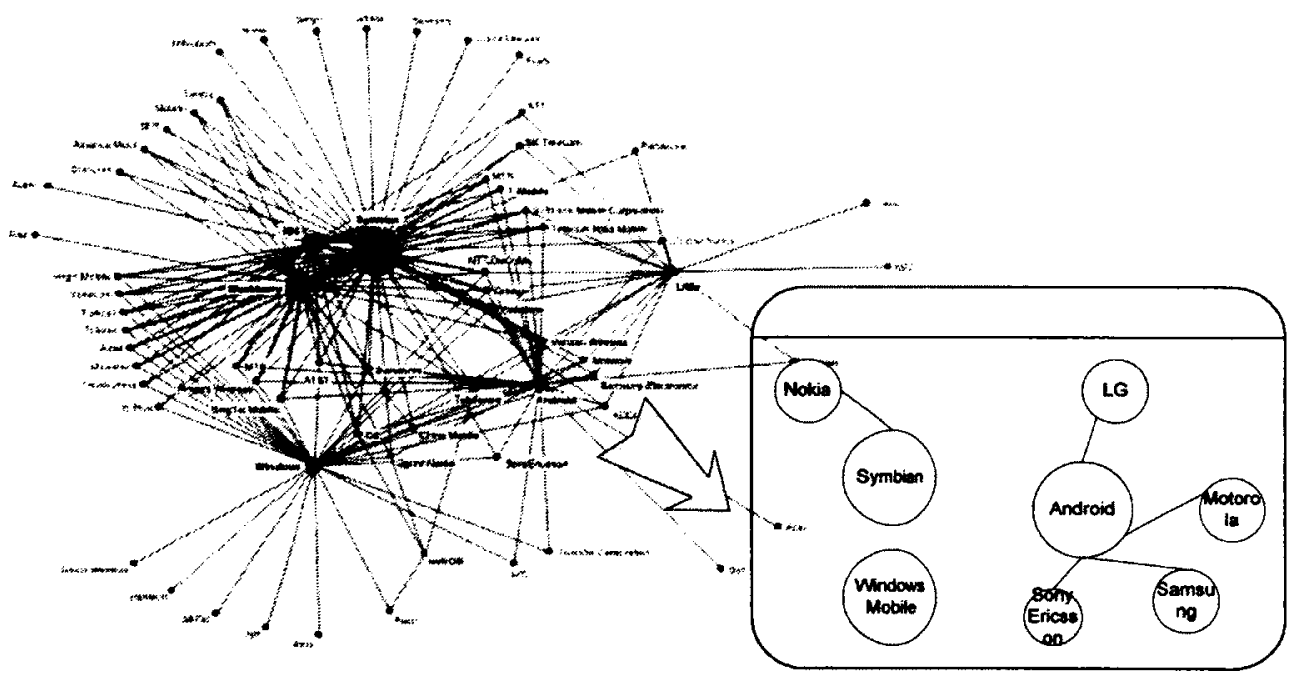

Figure 13: Visualization of Mobile Ecosystem, 2009 (Basole \& Karla, 2011)

Comparing Configuration 4 to the Basole and Karla (2011) visualization above, it can be seen that Symbian and Nokia do maintain their ties from previous years, while all the other MDMs choose to ally most closely with the newer Android platform. The one discrepancy is with Samsung, which the model predicts will choose Windows Mobile but it also shows a greater preference for Android.

In the context of industry knowledge, the affinity of most MDMs for Android makes sense for three reasons. Firstly, Android was the first legitimate competitor to the close iOS mobile OS platform, on which Apple's iPhone is based as it offered many of the technical capabilities that matched iOS. This was something that Symbian and Windows Mobile could not offer (Gandhewar \& Sheikh, 2010). Secondly, it was licensable and open source, which leveled the playing field somewhat between smaller and larger firms by reducing $\mathrm{R} \& \mathrm{D}$ and royalty costs. 
The kind of technology disruption that Android provided is not easy to explain with the base landscape model.

\subsubsection{0}

Table 8: Results of Base Landscape Model (2010)

\section{Configuration 1}

Microsoft

Nokia

LG

ZTE

Configuration 2

Microsoft

Nokia

LG

ZTE

Configuration 3

Microsoft

Motorola

Sony Ericsson

Huawei

Configuration 4

$\begin{array}{ll}\begin{array}{l}\text { Symbian } \\ \text { Motorola } \\ \text { Sony Ericsson } \\ \text { Huawei }\end{array} & \begin{array}{l}\text { Google } \\ \text { Samsung }\end{array} \\ \text { Symbian } & \begin{array}{l}\text { Google } \\ \text { Motorola } \\ \text { Samsung }\end{array} \\ & \begin{array}{l}\text { Sony Ericsson } \\ \text { Huawei }\end{array}\end{array}$

Symbian

Nokia

LG

ZTE
Microsoft

Samsung

Google

Samsung

Microsoft

Motorola

Huawei

Microsoft

Samsung

Symbian
Nokia
LG
ZTE

Configuration 5

Sony Ericsson

Configuration 6

Samsung
Symbian

Samsung

Symbian
Motorola
Sony Ericsson
Huawei

Google

Motorola

Sony Ericsson

Huawei

Google

Nokia

LG

ZTE

Google

Nokia

LG

ZTE 
The above table shows the possible configurations given from the model for 2010 . Once again, the smaller MDMs come together in an alliance while the bigger MDMs tend to distance themselves from other MDMs. The three larger MDMs by size, Samsung, Nokia and Huawei tend to be in separate alliances, with the smaller MDMs such as Motorola and Sony Ericsson showing a tendency to ally together with Huawei, while LG and ZTE allying with Nokia. Based on industry knowledge, Configuration 4 is the most likely to occur.

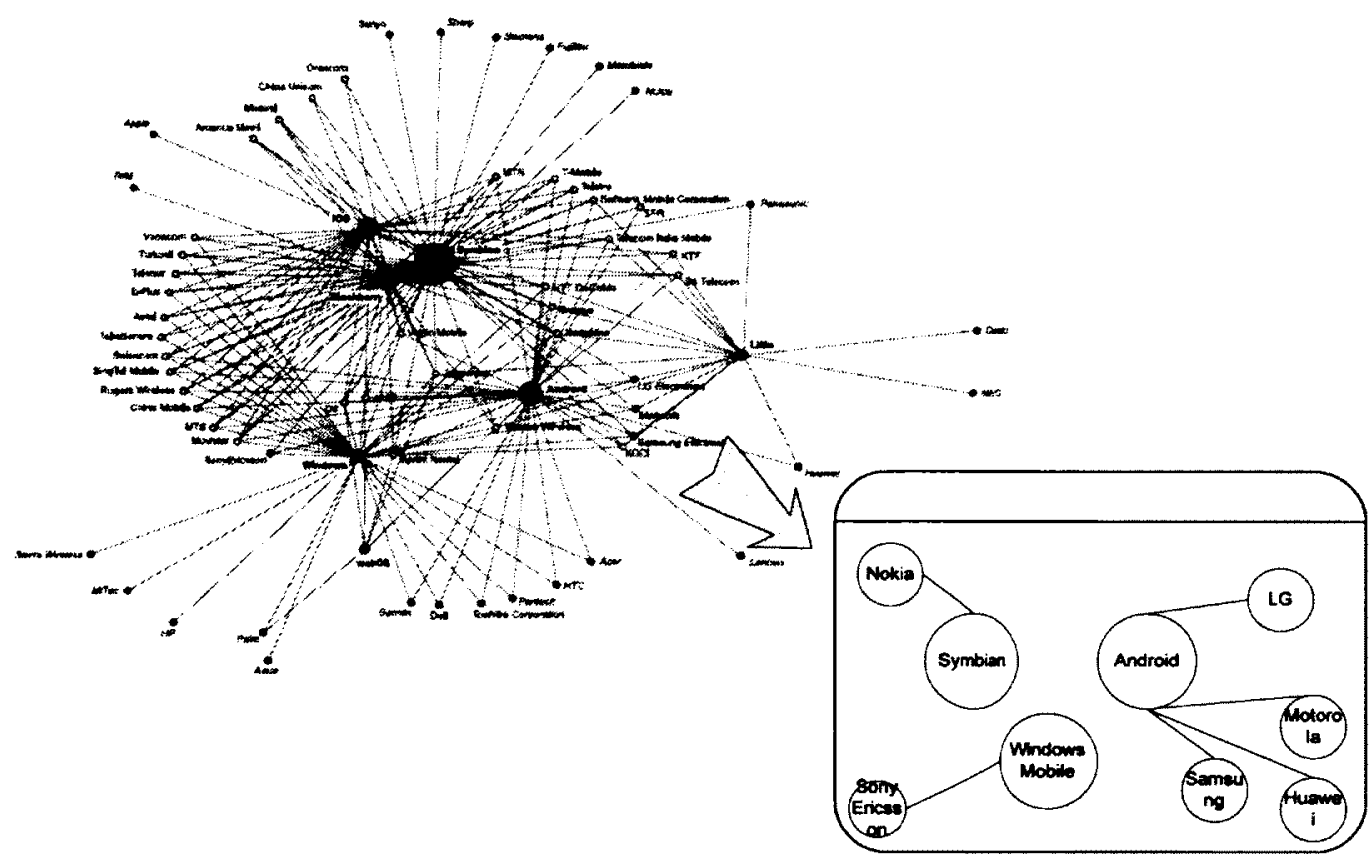

Figure 14: Visualization of Mobile Ecosystem, 2010 (Basole \& Karla, 2011)

Basole and Karla's visualizations show that the results of the model are mostly correct, with Huawei choosing Android as its mobile OS platform of choice, which is the main choice for Motorola as well. Nokia is tied solely to the Symbian platform. In the visualization, Sony Ericsson shows a greater preference for Windows Mobile, while 
Samsung shows a preference for Android, but is also tied to the Symbian and Windows Mobile platforms. These are both incorrectly described by the model results. ZTE is not represented in Basole \& Karla's visualization. 


\section{Chapter: Refining the Mobile Landscape Model}

While the results from the previous chapter clearly map to the actual network visualizations over the same time period, the model is lacking in that it does not clearly define mobile OS platform choices made by the MDMs. Therefore all possible combinations of MDM alliances and MPPs are returned as optimal results. In the current modeling of propensity characteristics of the MDMs and MPPs, there are clear negative propensities of MDMs to work together but the neutral MDM-MPP propensities cause the resulting optimal alliance structures given by the model to be ambiguous as to which MPP an MDM would pick. What it does show is the clearly demarcated alliances formed among the various MDMs. This in itself shows some meaningful information to MDMs as to what their strategic stance towards competing MDMs should be. However, in order to gain more value from the model, a more nuanced propensity matrix would have to be devised to show positive or negative propensities of MDMs towards various MPPs.

There may be multiple parameters on which to redefine MDM-MPP propensity. Examples include the technological capability of the mobile OS, the interoperability of the mobile OS software with the current hardware platforms used by the MDM, and the mobile OS used in previous phones released by the MDM.

Although there is research and Internet resources comparing mobile OS platform features fairly comprehensively (Gandhewar \& Sheikh, 2010), and there are clear advantages and disadvantages listed for the end user and mobile application developers, it is not clear if this will result in different propensities for MDMs. 
A more relevant measure might be the interoperability and compatibility of mobile OS with the MDMs existing hardware and phone architectures. However, this information is hard to obtain through public data sources and requires in depth knowledge of each MDMs historical hardware choices.

An easier way to measure the same compatibility might be through phone releases per year using a certain mobile OS platform. If a MDM has chosen a certain mobile OS in the past, it provides some indication that the firm had analyzed the compatibility of the OS with its hardware. In addition, it indicates that some research and development costs have already been incurred by the MDM to adopt the mobile OS platform, which may increase the preference of the company to continue with the same OS instead of making those capital expenditures in adopting a new mobile OS.

With this reasoning, the data on phone releases per year per manufacturer was obtained and the total phone releases in each year from 2006 to 2010, as well as the releases per mobile OS per manufacturer were tallied. This data was collected from http://www.phonescoop.com, which lists all phone releases by manufacturer. In order to generate a propensity metric, the ratio of phone releases on a certain mobile OS platform to the total phone releases in a year was used.

Note that not all phones released used one of the mobile OS platforms that we considered in our model. In fact, from 2006 to 2009 , a significant number of the phones released by MDMs used proprietary operating systems that were developed in house. This must be kept in mind when analyzing the results of the refined model.

The modified propensity values were input into the Propensity matrices and the calculations were re-iterated in $\mathrm{R}$, according to the equations given below 
PropensityMPP-MPP $=[1-(\alpha+\beta)]$

PropensityMPP-MDM $=[1-\alpha]+[$ Phone Releases on MPP(previous year)/Total Phone Releases $]$

PropensityMDM-MDM $=[1-(\alpha+\beta)]$

Figure 15: Modified Equations for Propensity

The raw data for phone release per manufacturer is given in the Appendix and also contain in the GitHub repository for this research.

\subsection{Results - Refined Model}

Making the modifications to the propensity metric to include the actual phone releases from the past year helped narrow down the optimal alliance structure for each year to one lowest energy solution. The following results were obtained for years 2006 to 2010 . 2006

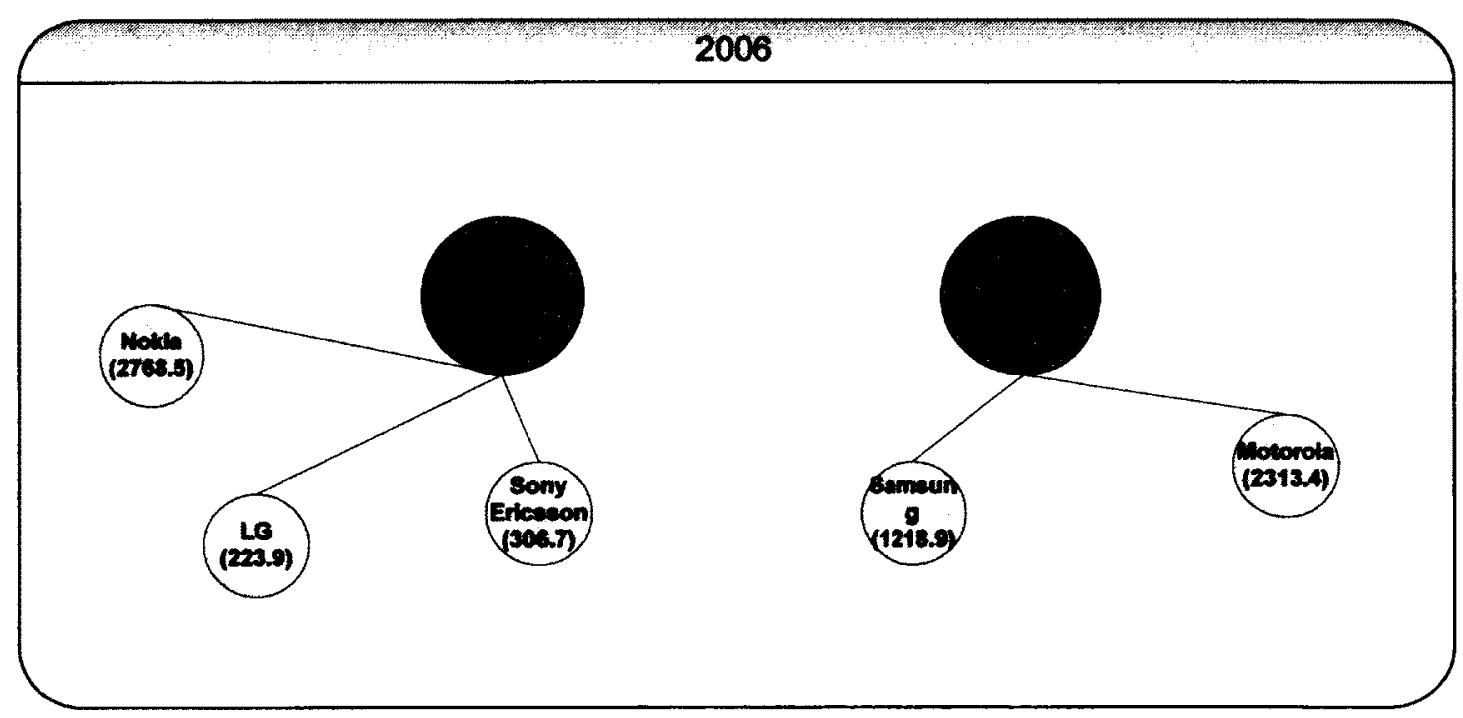

Figure 16: Optimal Result from Refined Landscape Model (2006) 
From the above, we can see that the two possibilities that were given by the base model now reduce to the one above, with the new propensity measures. This conclusively returns Configuration 2 as the optimal result, so that the decision to pick 2 over 1 no longer needs to be made based on industry knowledge. The result maps closely to the ties in the visualization, shown in Figure 8 before.

2007

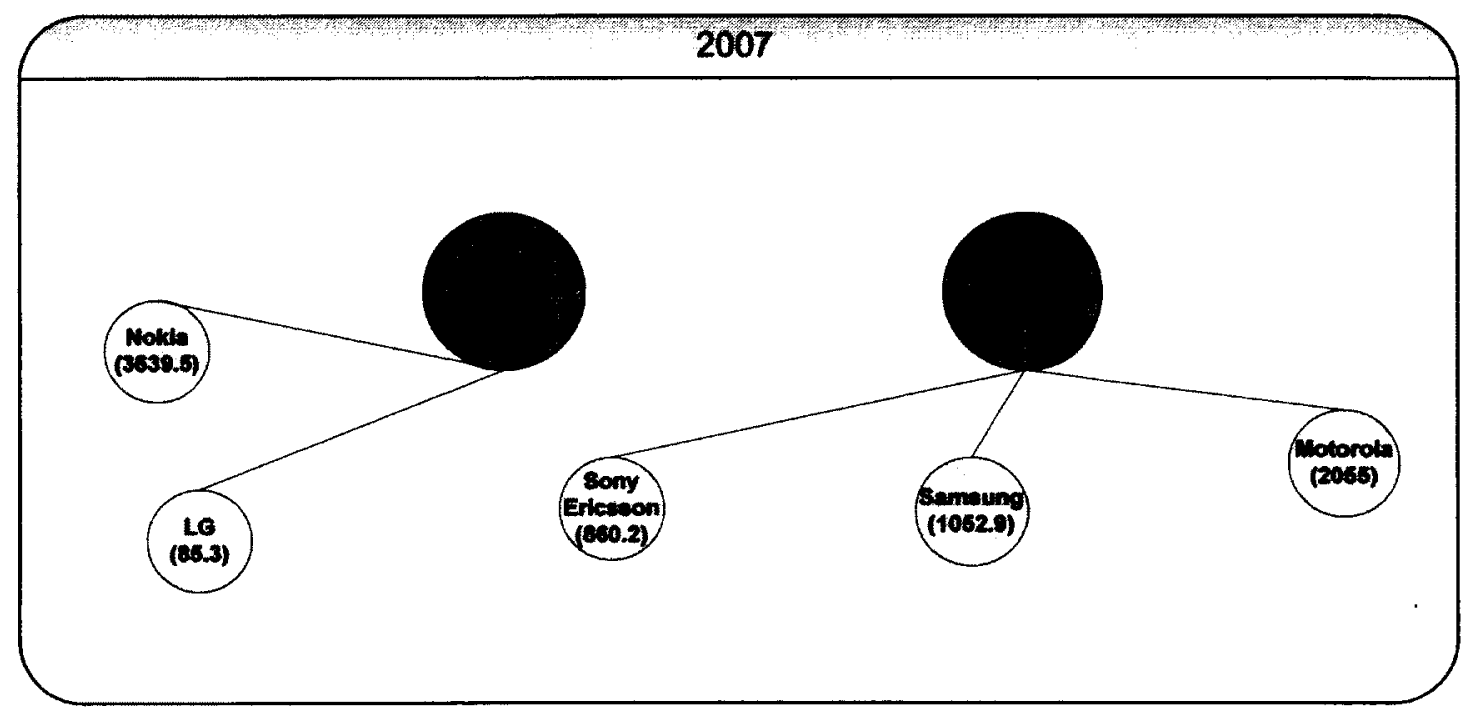

2008 


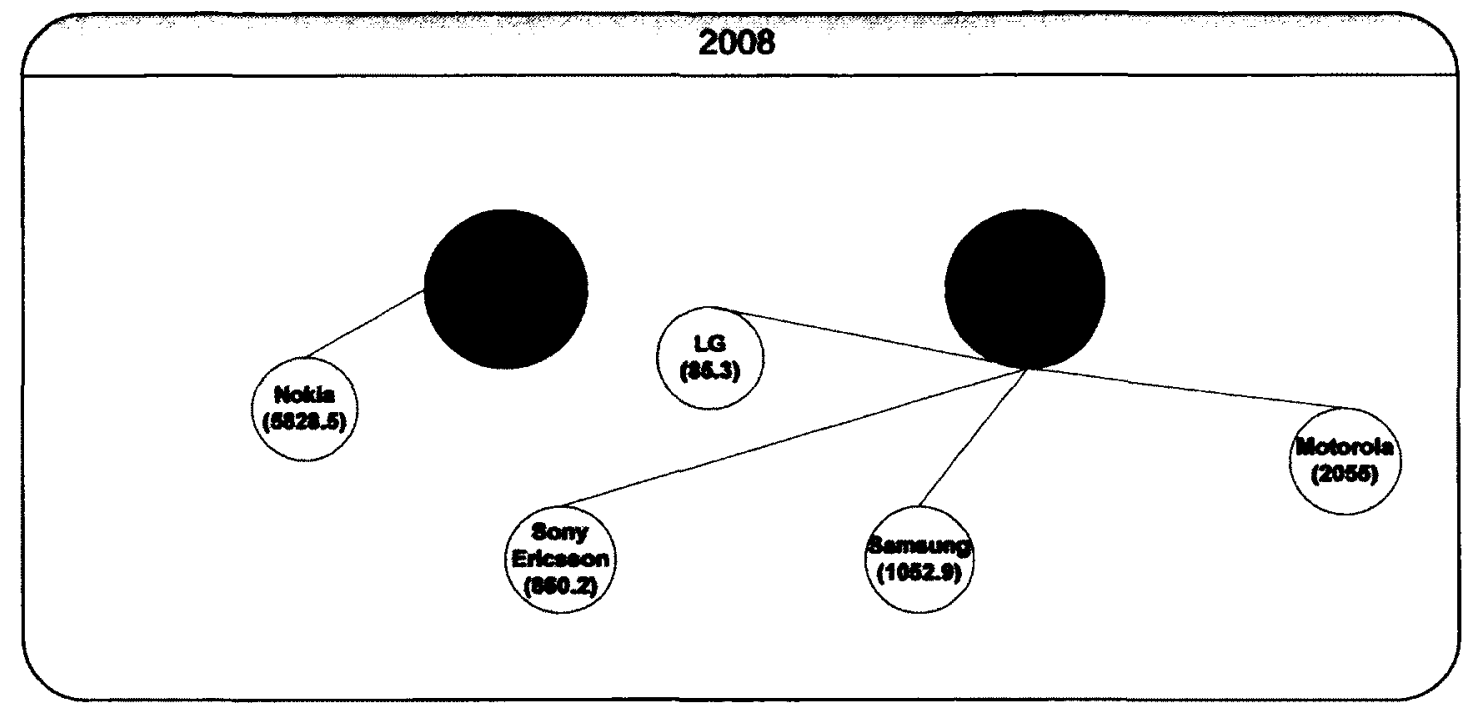

2009

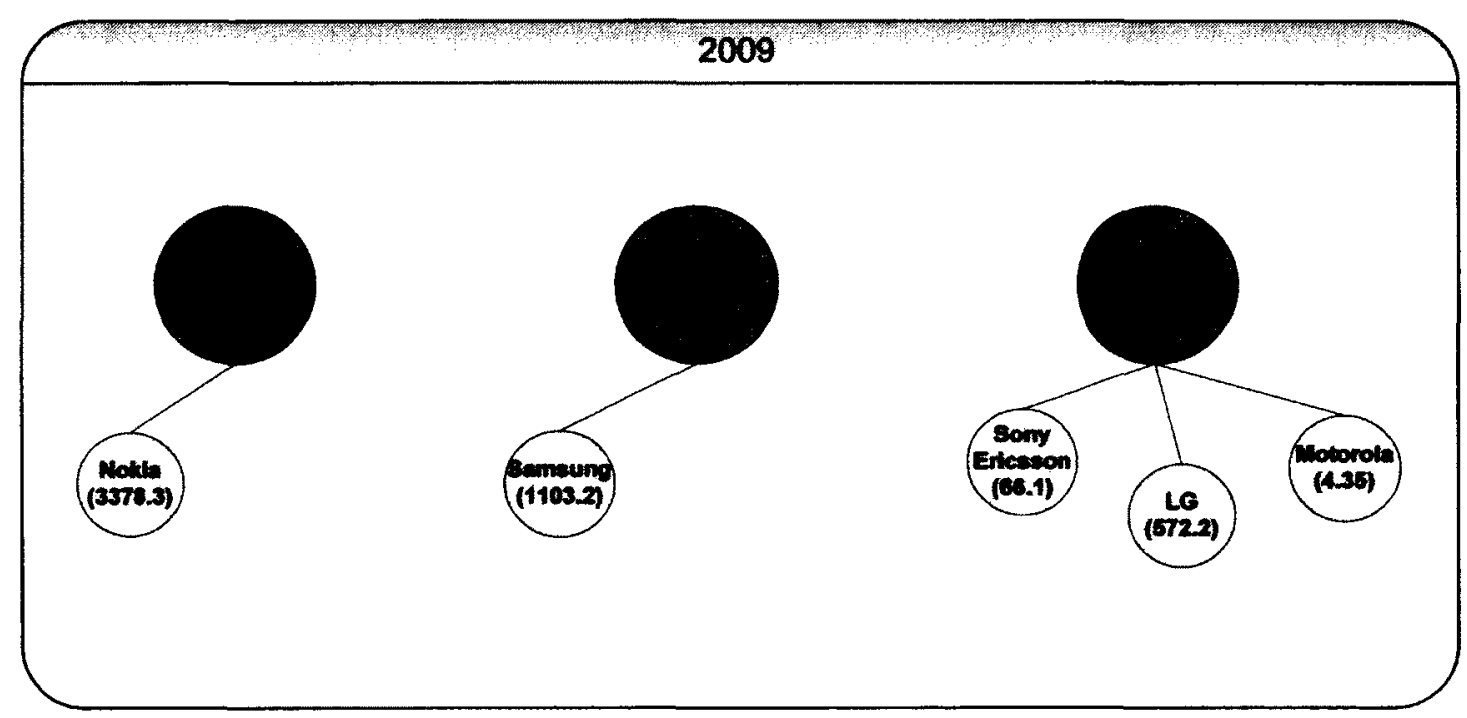

2010 


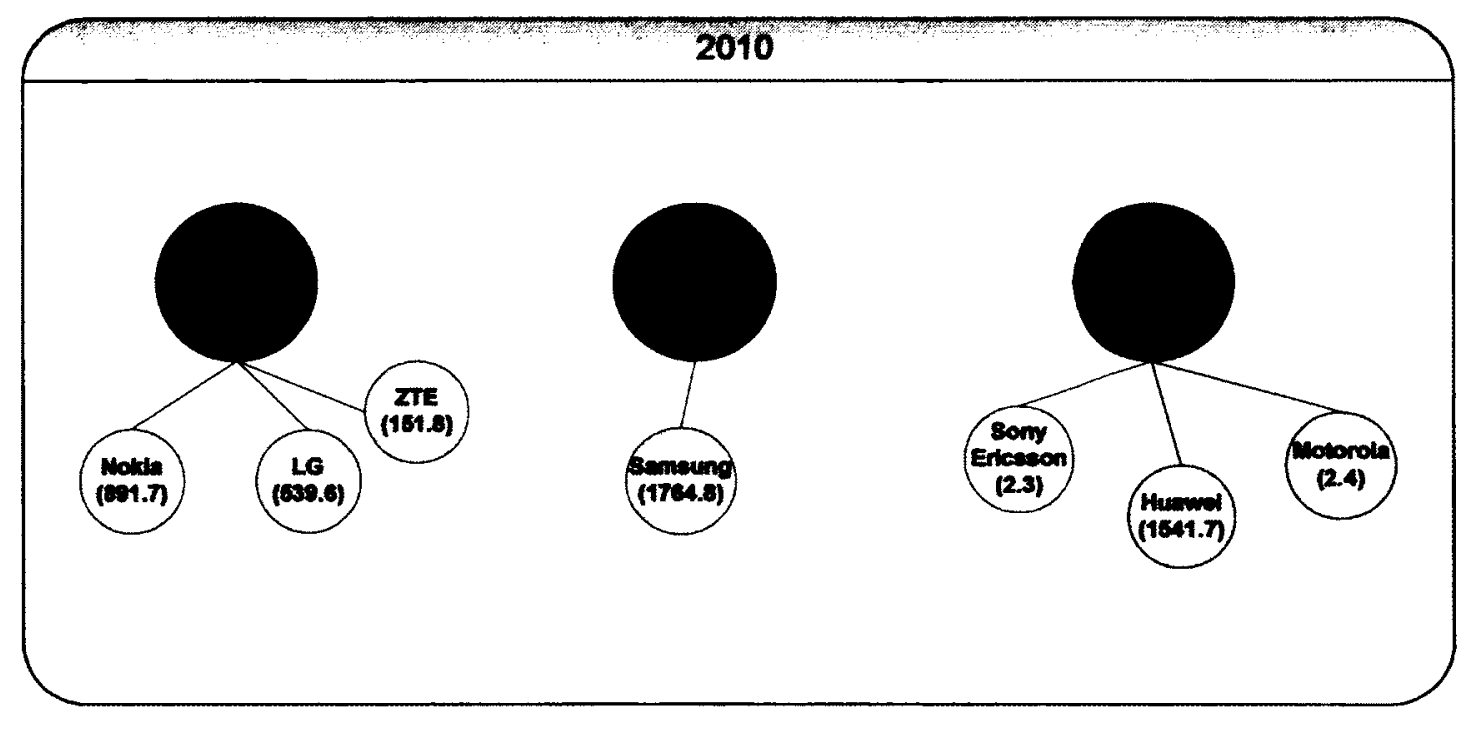

For 2006, 2007 and 2008, the results of the model match the results from the ecosystem visualization very well. In general, the affinity for a certain OS over another is captured in the results of the model as compared to the visualization.

In 2009 and 2010, Samsung is placed in the Windows alliance while Sony Ericsson is placed in the Android alliance, which are not the results reflected in the visualization. A possible explanation for this is that the choice between Windows and Android cannot be made solely on the basis of the size and propensity measures that we have used in the model. There may be other parameters that are outside the scope of the model that could explain the actual alliance structures that occurred. Another explanation for the discrepancy can be given based on the current information that is known about the mobile industry, i.e. Sony Ericsson's loss of market share due to delay in moving from Symbian to Android as their preferred mobile OS platform. Based on the results of the model, Sony Ericsson should have committed to Android much earlier. Thus, we see that perhaps the choices made in reality were not the optimal ones. 
Similar explanations can be used to explain why Samsung is shown in the Windows alliance instead of Android. The model is perhaps limited in the parameters that it takes into account when computing optimal alliance configurations. As such, based on other factors (for example, the technological strength of Android over Windows Mobile in 2008), Samsung made the decision to choose Android instead of Windows. 


\section{Chapter: Discussion of Results}

This chapter discusses the main insights gained from this research as well as the limitations of the landscape model.

\subsection{Insights}

\subsubsection{Basic Metrics are good indicators of alliance structure}

Using the mobile landscape model, this research has helped in verifying that the same principles used in the characterization of alliances in World War 2, the UNIX wars and the airline industry also apply to the mobile ecosystem. Basic measures such as the market share, revenue, operating profit and phone releases can provide fairly significant insights into the strategic alliances that a MDM should form. This makes landscape theory a very useful tool for any researcher or company strategist looking to get an overall view of the landscape in their respective industry. It has been proven to work in a variety of industries.

Two of the ways in the landscape theory model can be used in the mobile industry is to better understand the decisions made by firms (view of the past) and to input available data at any given point in time and get an indication for the alliances that should be chosen going forward (view of the future). The base model can also be refined to include any parameters of interest to the user, the results of which can be analyzed to determine the effect of that parameter on alliance formation in the mobile industry. In this way, the mobile landscape model provides a flexible framework which can be modified according to the objectives of the user. 


\subsubsection{Base model yielded great insights into the MDM alliances}

Just using a very basic model of size and propensity, the model yielded a clear indication of how MDMs would tend to ally with each other. This is very reflective of the actual strategies used by the mobile companies as shown in the Basole visualizations and as such, a great justification for the further use of the landscape model to study mobile ecosystem relationships.

\subsubsection{Refining model yielded very definitive results on the alliance structure} The variation and number of optimal alliance structures was significantly reduced as simple refinements to the model were done. This shows that researchers and management with access to more in depth industry data will be able to quickly find optimal alliance configurations and make quick strategic decisions based on these results.

The simplicity of the model is promising in that it does not require much data to get significant insight into inter-company dynamics and possible alliances.

\subsubsection{Time lag doesn't affect the results of the model}

Year after year, we see that with just the data from one year before, a result could be obtained that is fairly close to what the behavior of the firms is in that year. Therefore, there does not seem to be a significant time lag in the actions of the firms. The MDMs and MPPs make very quick moves and propensity can vary significantly from year to year. 
In hindsight, this is to be expected given the repeated descriptions of the mobile ecosystem as fast-changing, still converging and fragmented. Firms are still at the stage where they are looking for their optimal alliance and that could mean changing equations between firms in the ecosystem from year to year.

\subsubsection{Model suggests optimal decisions firms should make}

Based on certain premises of size and propensity, this model returns the optimal alliance structures that should result. In general, these paths are taken by firms but poor strategic decision making and late realization on the part of firms can leave a gap between what the optimal result would have been and the reality.

For example, the model showed Sony Ericsson switching from the Symbian alliance to Microsoft in the year before (2007) it actually made the move (2008). This shows a delay on Sony Ericsson's part in realizing that it had to re-align with new partners in order to strengthen its position in the ecosystem. Waiting too long to make the move has resulted in depleted market share for the firm as well as the eventual dissolution of the Sony Ericsson joint venture, with Sony buying out Ericsson's share of the business.

\subsubsection{Other insights contained in the results}

The model also shows the logic in certain other events that happened over the 5 year observation period.

An example of this is the continued close tie to the Android alliance that Motorola is shown to have since the mobile OS appeared on the market. Given the knowledge that we 
have now, that Google was looking to strengthen its position in the ecosystem by acquiring phone manufacturing know-how, it makes sense that it would have picked one of the MDMs tied to its own alliance to work with. Since LG and Sony Ericsson were already part of larger conglomerates, Motorola was an obvious and good choice for Google. The acquisition of Motorola Mobility by Google was announced in August 2011.

\subsubsection{Disruptive innovation is difficult to model}

A more disruptive technological disruption is hard to describe with this simple mobile landscape model. Two examples in the history of the mobile industry that cannot adequately be described are:

i) The introduction of the iPhone and the subsequent re-thinking of the smartphone as having a platform-application architecture. Apple provided a platform (iOS) on which is created a rich applications ecosystem, leveraged from its previous success with iTunes for the iPod. This opened the doors for a smarter breed of mobile OS platforms to come about, including Android and Windows Phone.

The emergence of Android as a choice for MDMs is thus hard to model as the paradigm shift towards a platform-app structure of the mobile phone software cannot be described as a simple propensity change.

The only part that could be modeled would be the entry of a large sized firm (Google) as an MPP and thereby the gravitation of the smaller MDMs toward partnering with a larger player to create a sizeable alliance. 
ii) The shutdown of the Symbian OS and the partnership between Nokia and Microsoft.

Another disruption that is not explained in the current model is the abrupt end of Nokia's support of the Symbian OS and adoption of Windows Mobile for its subsequent phone offerings. This switch in mobile platforms is most likely due to i) Symbian not having the technological capabilities to compete with Android and iOS and ii) Nokia's need to differentiate from its competitors in the mobile platform it uses. Since Symbian was not designed to offer the platform-app architecture of Android and iOS, Nokia was hard pressed to choose a platform that did offer that capability. Since its major competitors at the time (Samsung and Apple) were using Android and iOS respectively, it served Nokia's strategic interests to use its still significant installed base and resources to support the third place mobile platform, Windows Mobile, and compete head-to-head with the other manufacturers.

Since the refined model only takes into account the past platforms used, market share and profits, it can't account for the significant difference in the technological capability of a early mobile OS such as Symbian versus a newer OS such as Android.

The ability to account for these discrepancies in the model could be a very useful feature. For example, looking at the technical capabilities of the OS, the user experience and satisfaction ratings and business models of the MPPs might have given more insight into the disruptive changes that occurred within the ecosystem. 


\subsection{Limitations}

While the insights from using the landscape model are meaningful and significant, there are a number of limitations to the model that should not be disregarded.

1) One of the most important limitations of the model is the inability to describe various external factors that have an influence on how the firms in the system choose to ally with each other. In the research method, we described the reductions in scope performed in order to make a meaningful model.

Firstly, only mobile OS platforms that can be licensed are considered in the model, as only those can be used by MDMs in their handsets. This precludes the Apple (iOS) or Research In Motion (Blackberry OS) from being considered in this study, although they both hold significant market shares in the time period being considered (20062010). As such the effect of these mobile OS platform on the tactics employed by MDMs in the model are not measured. As an example, the introduction of Apple's iOS in their iPhone handset clearly marked the paradigm shift to the consideration of mobile OSs as application platforms rather than purely software platforms. This fundamental change in approach resulted in Google responding with the introduction of the Android platform, which was an open and licensed version of the iOS platform. Thus, the introduction of Android into the model in 2009 is a response more to the external effect of Apple's iOS rather than a direct competitive attempt to challenge Symbian or Windows Mobile. As such, there was wholesale adoption of the platform by all MDMs (except for Nokia), which is not described by the landscape model as it is. This is a key example of how external factors affect the decisions made by MDMs and MPPs that were considered. 
Secondly, another factor to consider is that not all phone releases by the MDMs in the time period 2006-2010 can be classified to be using one of the 3 MPPs considered. A great number of the phones released by all the MDMs use proprietary, presmartphone mobile operating systems. The sales of these low to mid-tier phones are aimed as differentiated market offerings in price sensitive markets, typically in the developing world. Considering that the size metric for MDMs consists of market share and operating profit, we have to consider that both of these measures include both smartphone shares and sales as well the sales of these other phones. Thus, a MDMs success in the low to mid tier market may effectively subsidize their smartphone releases, masking their true success in the smartphone market.

2) Another limitation of how the research scope is defined is that very small, niche MDMs (with less than $1 \%$ of market share individually), are not considered in the model. Although these MDMs form less than $1 \%$ of the market individually, they can hold as much as $25 \%$ of the market collectively. Therefore, the competitive forces that arise on the larger MDMs due to these smaller firms can be significant, especially in the low to mid tier phone market. This may not affect those MDMs that are focused on the high end phone (smartphone) market, but for those MDMs that have low-, mid- and high-end offerings, this is a force that is not measured in the landscape model currently.

3) A third limitation of the current model is that assigns at most one MPP per MDM, as the optimal platform and alliance for that MDM. In reality, visualizations of the 
ecosystem (Basole \& Karla, 2011) and market research reports by Vision Mobile show that some MDMs tend to hedge their bets by launching a few phones with different mobile OS platforms every year so as to be able to have the capability to adopt any of them as their platform of choice, if ever that decision has to be made in the future.

\subsection{Suggestions for Improvement}

The following are suggestions for improving the landscape model for the mobile industry and gaining a better understanding of the factors that influence alliance formation in this ecosystem.

1) A variety of different propensity parameters can be added to the model in order to measure their efficacy in predicting alliances of MDMs and MPPs. One suggestion of a parameter to be measured is the technological capability of each mobile OS platform and whether the platform is open or not.

2) A larger number of members of the actual mobile ecosystem can be included in the landscape model to make it an analytical tool for a greater number of players. 


\section{Chapter: Conclusions}

This research aims to enhance the arsenal of theoretical tools used to understand business ecosystems, focusing on the converging mobile ecosystem.

As shown in the previous chapters, not only does landscape theory provide meaningful results as a predictive and analytical model for device manufacturers to strategically pick mobile OS platforms for their future phone offerings, but shows great promise in its extensibility to various other players in the mobile ecosystem, as well as business ecosystems in general.

Through this research, landscape theory also shows itself to be a useful framework to employ where network theory has its limitations, namely, the lack of predictive ability for a still-evolving ecosystem and the requirement of significant industry knowledge to be a useful explanatory tool. With the landscape model, very basic, universal and publicly available business metrics such as market share and revenue can be used to gain substantial insight into how firms should align themselves to maximize their future success. In this way, the model is complementary to network theory in the understanding of ecosystem evolution.

Furthermore, the extensibility and flexibility of the model is such that adding industry specific knowledge (by refining the propensity definition accordingly) serves to further improve its efficacy. In this way landscape theory can be combined with network theory, 
measuring the network effects of different industry factors by modeling them as part of the size and propensity constructs, as appropriate.

By clearly showing the parallels between business ecosystems research and landscape theory viz. the study of alliance formation, and applying it to the mobile industry, this research shows the harmony between these two research streams and opens up new avenues for further research involving both these theoretical frameworks. It is hoped that this is of interest to researchers and scholars of both these fields and that future research be undertaken to further explore links between them and their applicability to other industries besides mobile.

In industry terms, this research may be of great relevance to strategic decision makers within private (businesses) and public organizations (government) seeking to better understand and plan the alliances into which they enter and also to understand the overall shape of the ecosystem to which they belong. The landscape theory model applied in the context of a business ecosystem is practical way in which they can achieve the goal of aligning themselves with the correct platform and partners to achieve success. 


\section{Appendices}

\section{Appendix A Landscape Theory - A Primer}

This is a detailed explanation of the mathematical modeling behind landscape theory and how calculations are carried out.

\section{A.1 Landscape Theory of Aggregation}

Aggregation refers to the organization of elements of a system into patterns that tend to put highly compatible elements together and less compatible elements apart (Axelrod \& Bennett, 1993). Landscape theory predicts how aggregation will lead to alignments among actors.

For a set of $\mathrm{n}$ actors in any application of the theory, three constructs, size, propensity and configuration are most important. The size of an actor, $s_{i}>0$, is a reflection of the importance of that actor to others. Size can be measured by demographic, industrial and economic factors, or any combination of these, depending on what is important in a particular application.

Another key premise is that 2 actors have a certain propensity to work together. That propensity will be positive if 2 actors get along well and negative if they don't. In the context of businesses forming alliances, strong competitors will have increased negative propensity to work together. Therefore propensity is a measure of how willing 2 firms are to be in the same alliance. Landscape theory assumes that propensity is a symmetric property of 2 actors in a system i.e. actor B will have the same propensity toward actor $\mathbf{A}$ that A has towards B. 
A configuration is a partition of the actors in a system into one of two groups. This can also be called an alliance structure. For all possible alliance structures, a distance matrix is created, which describes how the actors are arranged in 2 groups. For example, for 4 actors, A, B, C and D, two different configurations are shown below, with their corresponding distance matrices.

As mentioned in section 3.3.1 above, the following definition of distance is used to decide that value of distance per pair of actors.

$$
\begin{aligned}
\text { Distance, } D_{i j}= & \{0, \text { if } i \text { and } j \text { are in the same alliance } \\
& \{1 \text {, if } i \text { and } j \text { are not in the same } \\
& \text { alliance }
\end{aligned}
$$

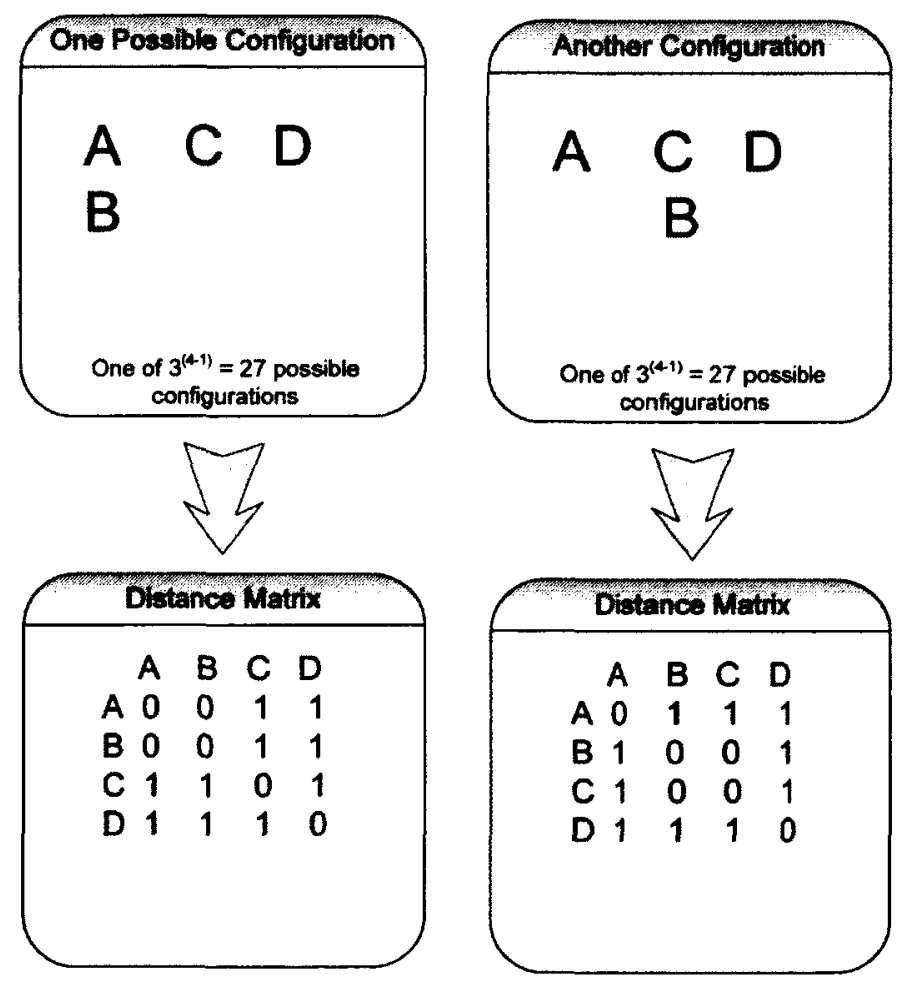

Figure 17: Configurations and corresponding Distance matrices 
By expressing size, propensity and distance in matrix form, it is possible calculate the utility or payoff function for each actor as well as the overall "energy" of each configuration.

The utility of actor $A$ is the total value of the size of all other actors multiplied by their propensity and distance from A. The terms in this sum are non-zero only if the distance between $\mathrm{A}$ and another firm is 1 i.e. they are in different alliances. Ideally, an actor would want all the actors with which it has a negative propensity to be in other alliances. Therefore a larger negative value of utility shows that the actor has the least amount of "frustration", as its competitors are in other alliances.

Since we must consider the frustrations of all the actors in the system, we use the weighted sum of the frustrations to define the energy of the system. By weighting the frustration of each actor by its size, we are giving more importance to larger sized actors (i.e. those with more clout) achieving the lowest frustration for themselves. The configuration or configurations that yield the lowest energy value are the ones that the landscape model defines as the most optimal alliance structures. These alliances result in the optimization of the frustration that each actor has to face. Axelrod and Bennett (1993) describe the energy values as a landscape of possible alliance configurations, of which the occurrences of the lowest energy value are local optimas or local minimas in the landscape, hence the name landscape theory. 
The theory is supported by the results of two cases: the alignment of seventeen European nations in the Second World War and membership in competing alliances of nine computer companies to set standards for Unix computer operating systems

\section{A.2 Matrix Mathematics}

In order to carry out the calculations for the energy, we need an easy way to manipulate the size, propensity and distance values for an application of the landscape model. In order to do this, we describe the size, propensity and distance as matrices.

Size is a $1 x n$ matrix, where $\mathrm{n}$ represents the number of actors being considered. Each column contains the size value for 1 actor in the system.

Propensity is a $n \times n$ matrix, which shows the pairwise propensities between $n$ actors. The columns describe the firms in the same order as in the size matrix.

Distance is a nxn matrix, which shows, for each configuration, what the distance between 2 actors is. The columns describe the firms in the same order as in the size matrix.

An example of how the matrices look is given below.
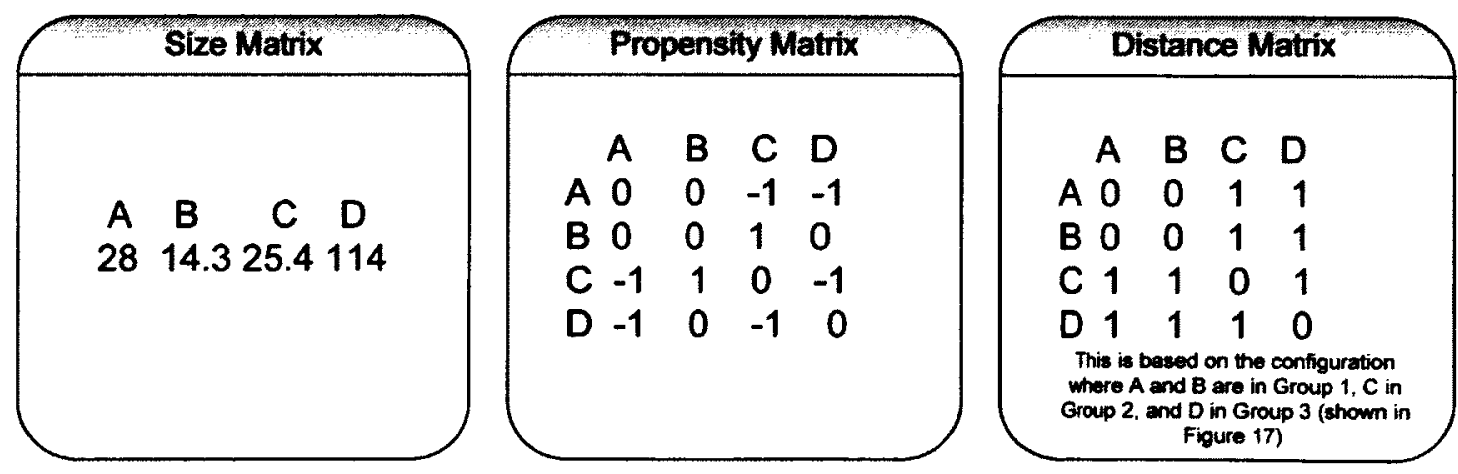
Figure 18: Example of Size, Propensity and Distance Matrices

To generate the Utility per actor, we calculate the Hadamard Product (element wise multiplication) of the Propensity and Distance matrices. This returns another nxn matrix. This matrix, multiplied by the Size matrix, returns the Utility function for each actor.
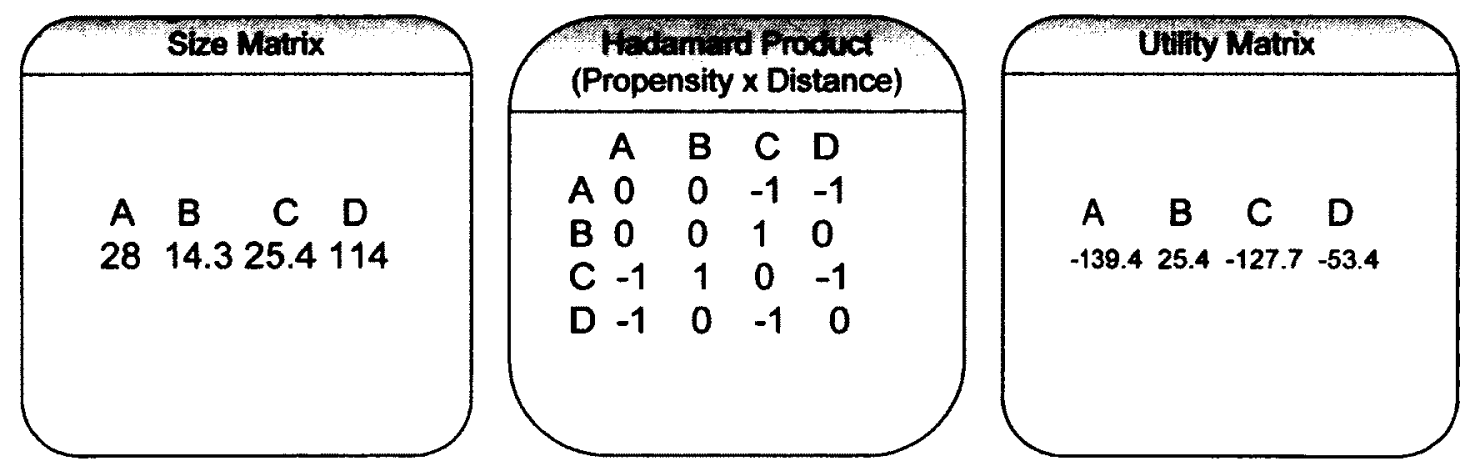

Figure 19: Calculation of the Utility values from Actors in the System

The Utility matrix, multiplied again by the Size matrix, gives the energy value for this particular configuration.
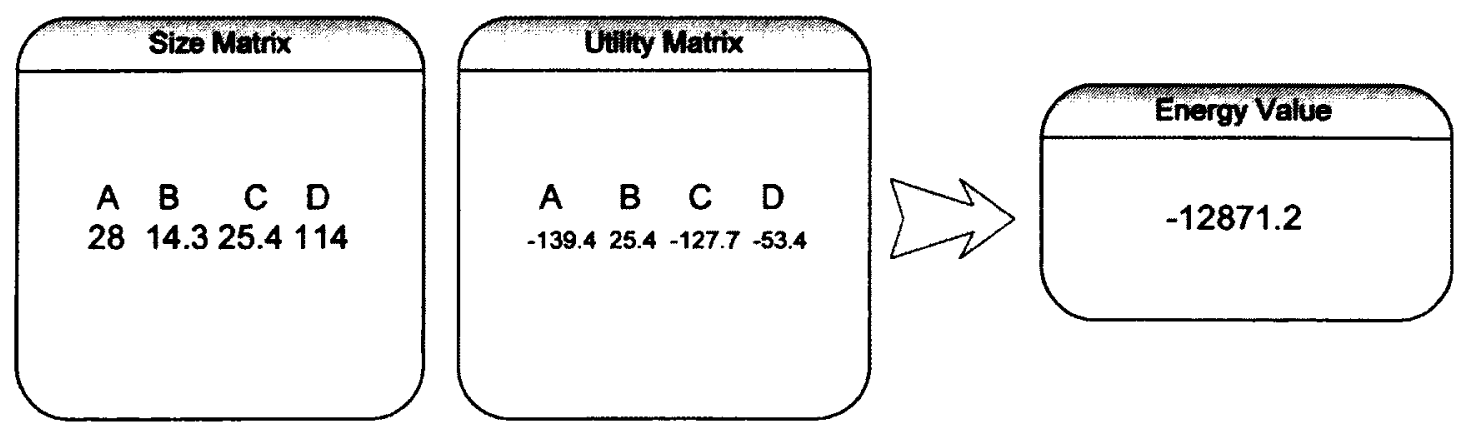

Figure 20: Calculation of Energy for a particular Configuration 
Once the energy values for all possible configurations are calculated, the configuration that returns the lowest energy value is determined as the optimal alliance structure for firms A, B, C and D to adopt. 


\section{Appendix B Data Collection and Processing}

This appendix contains the data used to calculate the size and propensity values that were used in the landscape model. It also describes how the data was used by the R scripts to generate the results.

\section{B.1 Raw Data}

The raw data collected is displayed in the tables below. All data is obtained from publicly available sources on the Internet. For data that was not recent, some use of the http://wayback.archive.org website was made.

The raw data is available in spreadsheet form from the GitHub repository for this thesis: shrutisatsangi/mobile_landscape

GitHub Inventory:

1. Spreadsheet containing the following metrics by year
a. Market Shares
b. Revenue
c. Operating Profits
d. Phone releases by manufacturer and mobile OS platform 


\section{B.2 Size and Propensities}

The size and propensity calculations for the base landscape model were made on the basis of the equations given below:

$$
\begin{gathered}
\text { Size } \left._{M P P}=1 / 2 \text { (Market Share }\right)+1 / 2 \text { (Revenue) } \\
\text { Size } \left._{M D M}=1 / 2 \text { (Market Share }\right)+1 / 2(\text { Operating Profit }) \\
\text { Propensity } \\
\text { Propensity } \\
\text { Propensityd }=[1-(\alpha+\beta)] \\
\text { Propensity }=[1-\alpha]
\end{gathered}
$$

For the refined model, the propensity equation for MPPs and MDMs was modified as follows:

Propensity $_{\text {MPP-MDM }}=[1-\alpha]+[($ Phone Releases on MPP/Total Phone Releases $)]$

As defined in Axelrod et. al. (1995), for all the equations above, $\alpha=1$ and $\beta=1$.

Below are the Size and Propensity tables for 2006 to 2010.

2006

Size:

\begin{tabular}{|l|r|r|l|r|}
\hline 2006 & $\begin{array}{l}\text { Revenue } \\
\text { (millions } \\
\text { USD) }\end{array}$ & $\begin{array}{l}\text { Market } \\
\text { Share }\end{array}$ & $\begin{array}{l}\text { Operating } \\
\text { Profit } \\
\text { (millions } \\
\text { USD) }\end{array}$ & \multicolumn{1}{l|}{ Size } \\
\hline Microsoft & 262 & 17 & & 139.5 \\
\hline Symbian & 114.8 & 51 & & 82.9 \\
\hline Nokia & & 34.9 & 5502 & 2768.45 \\
\hline Motorola & & 21.8 & 4605 & 2313.4 \\
\hline Samsung & & 11.7 & 2426 & 1218.85 \\
\hline Sony Ericsson & 6.3 & 607 & 306.65 \\
\hline LG & & 6.8 & 441 & 223.9 \\
\hline
\end{tabular}


Propensity (Base):

\begin{tabular}{|l|r|r|r|r|r|r|r|}
\hline 2006 & MS & \multicolumn{1}{l|}{ Symbian } & \multicolumn{1}{l|}{ Nokia } & \multicolumn{1}{l|}{ Motorola } & \multicolumn{1}{l|}{ Samsung } & \multicolumn{1}{l|}{ Sony E } & \multicolumn{1}{l|}{ LG } \\
\hline MS & 0 & -1 & 0 & 0 & 0 & 0 & 0 \\
\hline Symbian & -1 & 0 & 0 & 0 & 0 & 0 & 0 \\
\hline Nokia & 0 & 0 & 0 & -1 & -1 & -1 & -1 \\
\hline Motorola & 0 & 0 & -1 & 0 & -1 & -1 & -1 \\
\hline Samsung & 0 & 0 & -1 & -1 & 0 & -1 & -1 \\
\hline Sony E & 0 & 0 & -1 & -1 & -1 & 0 & -1 \\
\hline LG & 0 & 0 & -1 & -1 & -1 & -1 & 0 \\
\hline
\end{tabular}

Propensity (Refined):

\begin{tabular}{|l|r|r|r|r|r|r|r|}
\hline \multicolumn{1}{|c|}{2006} & \multicolumn{1}{l|}{ MS } & \multicolumn{1}{l|}{ Symbian } & \multicolumn{1}{l|}{ Nokia } & \multicolumn{1}{l|}{ Motorola } & \multicolumn{1}{l|}{ Samsung } & \multicolumn{1}{l|}{ Sony E } & \multicolumn{1}{l|}{ LG } \\
\hline MS & 0 & -1 & 0 & 0.07 & 0.06 & 0 & 0 \\
\hline Symbian & -1 & 0 & 0.1 & 0 & 0.02 & 0 & 0 \\
\hline Nokia & 0 & 0.1 & 0 & -1 & -1 & -1 & -1 \\
\hline Motorola & 0.07 & 0 & -1 & 0 & -1 & -1 & -1 \\
\hline Samsung & 0.06 & 0.02 & -1 & -1 & 0 & -1 & -1 \\
\hline Sony E & 0 & 0 & -1 & -1 & -1 & 0 & -1 \\
\hline LG & 0 & 0 & -1 & -1 & -1 & -1 & 0 \\
\hline
\end{tabular}

2007

Size:

\begin{tabular}{|l|r|r|r|r|}
\hline 2007 & Revenue & $\begin{array}{l}\text { Market } \\
\text { Share }\end{array}$ & $\begin{array}{l}\text { Operating } \\
\text { Profit }\end{array}$ & \multicolumn{1}{l|}{ Size } \\
\hline Microsoft & 377 & 10.6 & & 193.8 \\
\hline Symbian & 165.2 & 61.2 & & 113.2 \\
\hline Nokia & & 34.9 & 7244 & 3639.45 \\
\hline Motorola & & 18 & 4092 & 2055 \\
\hline Samsung & & 11.86 & 2094 & 1052.93 \\
\hline \multicolumn{2}{|l|}{ Sony Ericsson } & 7.49 & 1713 & 860.245 \\
\hline LG & & 6.67 & 164 & 85.335 \\
\hline
\end{tabular}


Propensity (Base):

\begin{tabular}{|l|r|r|r|r|r|r|r|}
\hline 2007 & MS & Symbian & \multicolumn{1}{l|}{ Nokia } & Motorola & Samsung & \multicolumn{1}{l|}{ Sony E } & LG \\
\hline MS & 0 & -1 & 0 & 0 & 0 & 0 & 0 \\
\hline Symbian & -1 & 0 & 0 & 0 & 0 & 0 & 0 \\
\hline Nokia & 0 & 0 & 0 & -1 & -1 & -1 & -1 \\
\hline Motorola & 0 & 0 & -1 & 0 & -1 & -1 & -1 \\
\hline Samsung & 0 & 0 & -1 & -1 & 0 & -1 & -1 \\
\hline Sony E & 0 & 0 & -1 & -1 & -1 & 0 & -1 \\
\hline LG & 0 & 0 & -1 & -1 & -1 & -1 & 0 \\
\hline
\end{tabular}

Propensity (Refined):

\begin{tabular}{|l|r|r|r|r|r|r|r|}
\hline \multicolumn{1}{|c|}{2007} & \multicolumn{1}{l|}{ MS } & Symbian & Nokia & Motorola & Samsung & Sony E & LG \\
\hline MS & 0 & -1 & 0 & 0 & 0.05 & 0 & 0 \\
\hline Symbian & -1 & 0 & 0.3 & 0 & 0 & 0 & 0 \\
\hline Nokia & 0 & 0.3 & 0 & -1 & -1 & -1 & -1 \\
\hline Motorola & 0 & 0 & -1 & 0 & -1 & -1 & -1 \\
\hline Samsung & 0.05 & 0 & -1 & -1 & 0 & -1 & -1 \\
\hline Sony E & 0 & 0 & -1 & -1 & -1 & 0 & -1 \\
\hline LG & 0 & 0 & -1 & -1 & -1 & -1 & 0 \\
\hline
\end{tabular}

\section{8}

Size:

\begin{tabular}{|l|r|r|r|r|}
\hline 2008 & \multicolumn{1}{|l|}{ Rev } & $\begin{array}{l}\text { Market } \\
\text { Share }\end{array}$ & $\begin{array}{l}\text { Operating } \\
\text { Profit }\end{array}$ & \multicolumn{1}{l|}{ Size } \\
\hline Microsoft & 6083 & 13 & & 3048 \\
\hline Symbian & 194.3 & 67 & & 130.65 \\
\hline Nokia & & 38.98 & 11618 & 5828.49 \\
\hline Motorola & & 14.2 & 0 & 7.1 \\
\hline Samsung & & 13.4 & 2954 & 1483.7 \\
\hline Sony Ericsson & 8.8 & 2290 & 1149.4 \\
\hline LG & & 6.8 & 1001 & 503.9 \\
\hline
\end{tabular}


Propensity (Base):

\begin{tabular}{|l|r|r|r|r|r|r|r|}
\hline & MS & Symbian & \multicolumn{1}{l|}{ Nokia } & Motorola & Samsung & Sony E & LG \\
\hline MS & 0 & -1 & 0 & 0 & 0 & 0 & 0 \\
\hline Symbian & -1 & 0 & 0 & 0 & 0 & 0 & 0 \\
\hline Nokia & 0 & 0 & 0 & -1 & -1 & -1 & -1 \\
\hline Motorola & 0 & 0 & -1 & 0 & -1 & -1 & -1 \\
\hline Samsung & 0 & 0 & -1 & -1 & 0 & -1 & -1 \\
\hline Sony E & 0 & 0 & -1 & -1 & -1 & 0 & -1 \\
\hline LG & 0 & 0 & -1 & -1 & -1 & -1 & 0 \\
\hline
\end{tabular}

Propensity (Refined):

\begin{tabular}{|c|c|c|c|c|c|c|c|}
\hline 2008 & MS & Symbian & Nokia & Motorola & Samsung & Sony $\mathrm{E}$ & LG \\
\hline MS & 0 & -1 & 0 & 0.07 & 0.07 & 0 & 0 \\
\hline Symbian & -1 & 0 & 0.46 & 0 & 0 & 0 & 0 \\
\hline Nokia & 0 & 0.46 & 0 & -1 & -1 & -1 & -1 \\
\hline Motorola & 0.07 & 0 & -1 & 0 & -1 & -1 & -1 \\
\hline Samsung & 0.07 & 0 & -1 & -1 & 0 & -1 & -1 \\
\hline Sony $\mathrm{E}$ & 0 & 0 & -1 & -1 & -1 & 0 & -1 \\
\hline LG & 0 & 0 & -1 & -1 & -1 & -1 & 0 \\
\hline
\end{tabular}

2009

Size:

\begin{tabular}{|l|r|r|r|r|}
\hline 2009 & \multicolumn{1}{|l|}{ Rev } & $\begin{array}{l}\text { Market } \\
\text { Share }\end{array}$ & $\begin{array}{l}\text { Operating } \\
\text { Profit }\end{array}$ & \multicolumn{1}{l|}{ Size } \\
\hline Microsoft & 8140 & 11.8 & & $\mathbf{4 0 7 5 . 9}$ \\
\hline Symbian & 291.7 & 52.4 & & 172.05 \\
\hline Nokia & & 38.6 & 6718 & 3378.3 \\
\hline Motorola & & 8.7 & 0 & 4.35 \\
\hline Samsung & & 16.3 & 2190 & 1103.15 \\
\hline $\begin{array}{l}\text { Sony } \\
\text { Ericsson }\end{array}$ & & 7.6 & 124.5 & 66.05 \\
\hline LG & & 8.4 & 1136 & 572.2 \\
\hline Google & 4227 & 0.5 & & 2113.75 \\
\hline
\end{tabular}


Propensity (Base):

\begin{tabular}{|l|r|r|r|r|r|r|r|r|}
\hline 2009 & MS & \multicolumn{1}{|l|}{ Symbian } & \multicolumn{1}{l|}{ Google } & \multicolumn{1}{l|}{ Nokia } & Motorola & Samsung & \multicolumn{1}{l|}{ Sony E } & LG \\
\hline MS & 0 & -1 & -1 & 0 & 0 & 0 & 0 & 0 \\
\hline Symbian & -1 & 0 & -1 & 0 & 0 & 0 & 0 & 0 \\
\hline Google & -1 & -1 & 0 & 0 & 0 & 0 & 0 & 0 \\
\hline Nokia & 0 & 0 & 0 & 0 & -1 & -1 & -1 & -1 \\
\hline Motorola & 0 & 0 & 0 & -1 & 0 & -1 & -1 & -1 \\
\hline Samsung & 0 & 0 & 0 & -1 & -1 & 0 & -1 & -1 \\
\hline Sony E & 0 & 0 & 0 & -1 & -1 & -1 & 0 & -1 \\
\hline LG & 0 & 0 & 0 & -1 & -1 & -1 & -1 & 0 \\
\hline
\end{tabular}

Propensity (Refined):

\begin{tabular}{|l|r|r|r|r|r|r|r|r|}
\hline \multicolumn{1}{|c|}{2009} & \multicolumn{1}{|c|}{ MS } & Symbian & Google & Nokia & Motorola & Samsung & Sony E & \multicolumn{1}{l|}{ LG } \\
\hline MS & 0 & -1 & -1 & 0 & 0 & 0.09 & 0 & 0.05 \\
\hline Symbian & -1 & 0 & -1 & 0.48 & 0 & 0 & 0 & 0 \\
\hline Google & -1 & -1 & 0 & 0 & 0 & 0 & 0 & 0 \\
\hline Nokia & 0 & 0.48 & 0 & 0 & -1 & -1 & -1 & -1 \\
\hline Motorola & 0 & 0 & 0 & -1 & 0 & -1 & -1 & -1 \\
\hline Samsung & 0.09 & 0 & 0 & -1 & -1 & 0 & -1 & -1 \\
\hline Sony E & 0 & 0 & 0 & -1 & -1 & -1 & 0 & -1 \\
\hline LG & 0.05 & 0 & 0 & -1 & -1 & -1 & -1 & 0 \\
\hline
\end{tabular}

\section{0}

Size:

\begin{tabular}{|l|r|r|l|r|}
\hline 2010 & \multicolumn{1}{|l|}{ Rev } & $\begin{array}{l}\text { Market } \\
\text { Share }\end{array}$ & $\begin{array}{l}\text { Operating } \\
\text { Profit }\end{array}$ & \multicolumn{1}{l|}{ Size } \\
\hline Microsoft & 7753 & 8.7 & & 3880.9 \\
\hline Symbian & 283.1 & 46.9 & & 165 \\
\hline Nokia & & 36.4 & 1747 & 891.7 \\
\hline Motorola & & 4.8 & 0 & 2.4 \\
\hline Samsung & & 19.5 & 3510 & 1764.8 \\
\hline Sony Ericsson & & 4.5 & 0 & 2.3 \\
\hline LG & & 10.1 & 1069 & 539.6 \\
\hline ZTE & & 1.3 & 302.3 & 151.8 \\
\hline Huawei & & 1.0 & 3082.3 & 1541.7 \\
\hline Google & 6520 & 3.9 & & 3262 \\
\hline
\end{tabular}


Propensity (Base):

\begin{tabular}{|l|r|r|r|r|r|r|r|r|r|r|}
\hline & MS & Symbian & Google & Nokia & Motorola & Samsung & Sony E & LG & ZTE & Huawei \\
\hline MS & 0 & -1 & -1 & 0 & 0 & 0 & 0 & 0 & 0 & 0 \\
\hline Symbian & -1 & 0 & -1 & 0 & 0 & 0 & 0 & 0 & 0 & 0 \\
\hline Google & -1 & -1 & 0 & 0 & 0 & 0 & 0 & 0 & 0 & 0 \\
\hline Nokia & 0 & 0 & 0 & 0 & -1 & -1 & -1 & -1 & -1 & -1 \\
\hline Motorola & 0 & 0 & 0 & -1 & 0 & -1 & -1 & -1 & -1 & -1 \\
\hline Samsung & 0 & 0 & 0 & -1 & -1 & 0 & -1 & -1 & -1 & -1 \\
\hline SonyE & 0 & 0 & 0 & -1 & -1 & -1 & 0 & -1 & -1 & -1 \\
\hline LG & 0 & 0 & 0 & -1 & -1 & -1 & -1 & 0 & -1 & -1 \\
\hline ZTE & 0 & 0 & 0 & -1 & -1 & -1 & -1 & -1 & 0 & -1 \\
\hline Huawei & 0 & 0 & 0 & -1 & -1 & $-1-$ & -1 & -1 & -1 & 0 \\
\hline
\end{tabular}

Propensity (Refined):

\begin{tabular}{|l|r|r|r|r|r|r|r|r|r|r|}
\hline \multicolumn{1}{|c|}{2010} & \multicolumn{1}{l|}{ MS } & Symbian & Google & Nokia & Motorola & Samsung & Sony E & LG & \multicolumn{1}{l|}{ ZTE } & Huawei \\
\hline MS & 0 & -1 & -1 & 0 & 0 & 0.09 & 0 & 0.05 & 0 & 0 \\
\hline Symbian & -1 & 0 & -1 & 0.44 & 0 & 0 & 0.25 & 0 & 0 & 0 \\
\hline Google & -1 & -1 & 0 & 0 & 0.25 & 0.05 & 0.25 & 0 & 0 & 0 \\
\hline Nokia & 0 & 0.44 & 0 & 0 & -1 & -1 & -1 & -1 & -1 & -1 \\
\hline Motorola & 0 & 0 & 0.25 & -1 & 0 & -1 & -1 & -1 & -1 & -1 \\
\hline Samsung & 0.09 & 0 & 0.05 & -1 & -1 & 0 & -1 & -1 & -1 & -1 \\
\hline Sony E & 0 & 0 & 0.25 & -1 & -1 & -1 & 0 & -1 & -1 & -1 \\
\hline LG & 0.05 & 0 & 0 & -1 & -1 & -1 & -1 & 0 & -1 & -1 \\
\hline ZTE & 0 & 0 & 0 & -1 & -1 & -1 & -1 & -1 & 0 & -1 \\
\hline Huawei & 0 & 0 & 0 & -1 & -1 & -1 & -1 & -1 & -1 & 0 \\
\hline
\end{tabular}




\section{B.3 Data Processing in $\mathbf{R}$}

The Size and Propensity information was captured above was entered into Comma Separated Values (CSV) files, labeled by year. An example of the 2006 files is shown below. All files and scripts discussed below are available on GitHub in the repository: shrutisatsangi/mobile_landscape

Size_2006.csv file

Microsoft, Symbian, Nokia, Motorola, Samsung, Sony Ericsson, LG $139.5,82.9,2768.45,2313.4,1218.85,306.65,223.9$

Propensities_base_2006.csv file

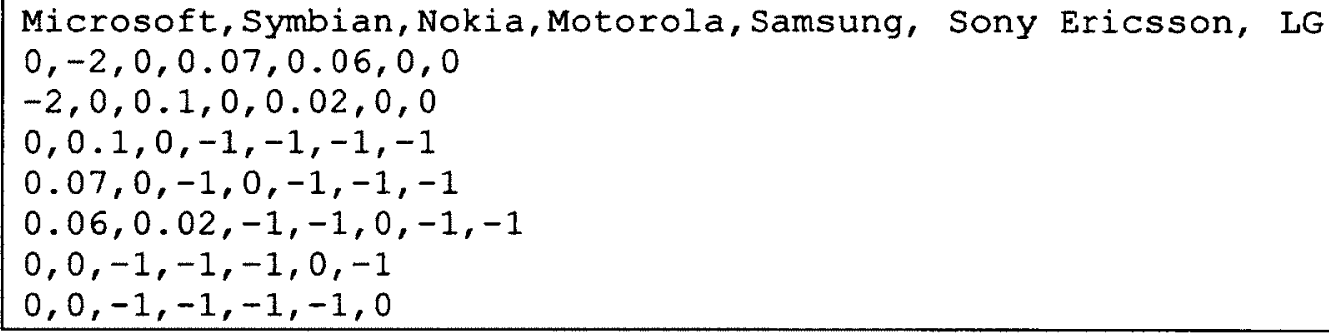

The CSV files were accessed via the R script to generate Size and Propensity matrices in R. The Distance matrix was generated and these three matrices were used to calculate the Utility value for each company and Energy of the system. This was done for each possible combination of companies possible, given a 2 alliance or 3 alliance system. 


\section{R script for 2 alliance energy calculation:}

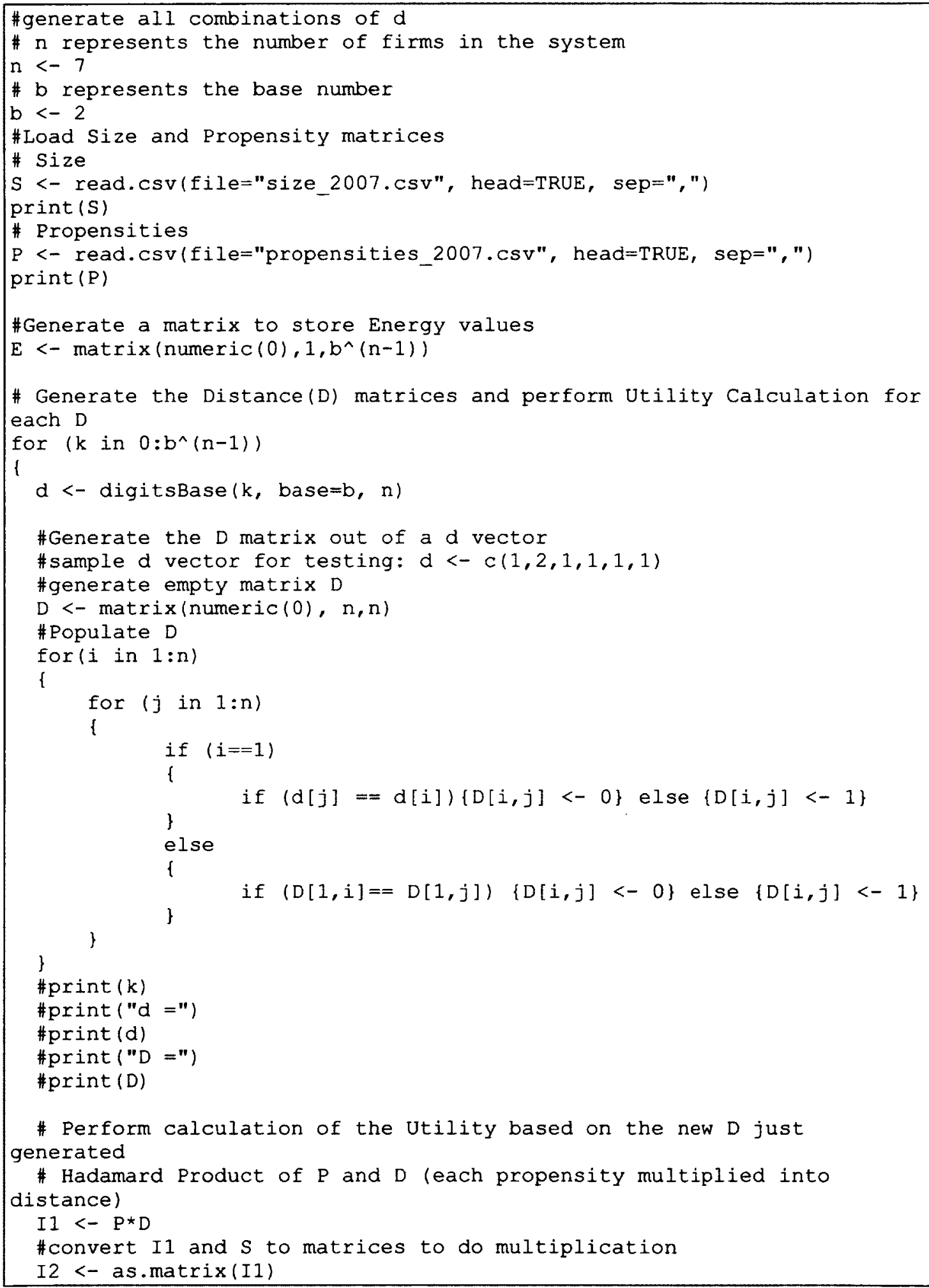




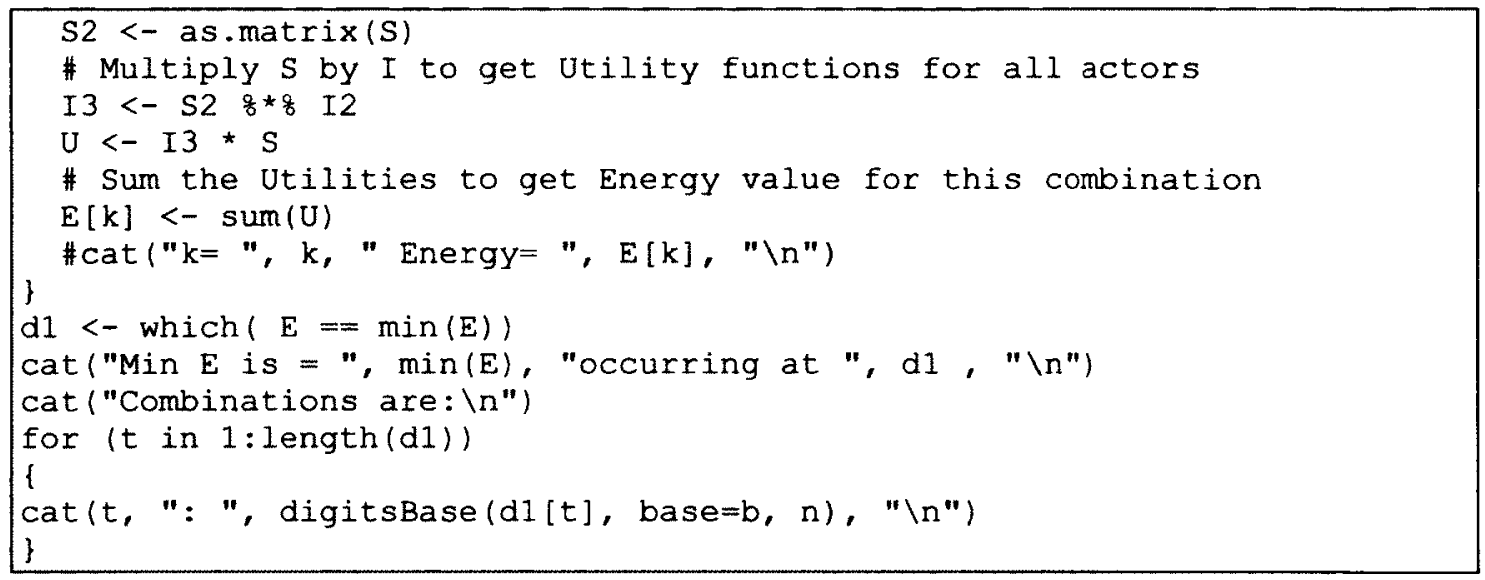

\section{R script for 3 alliance energy calculation:}

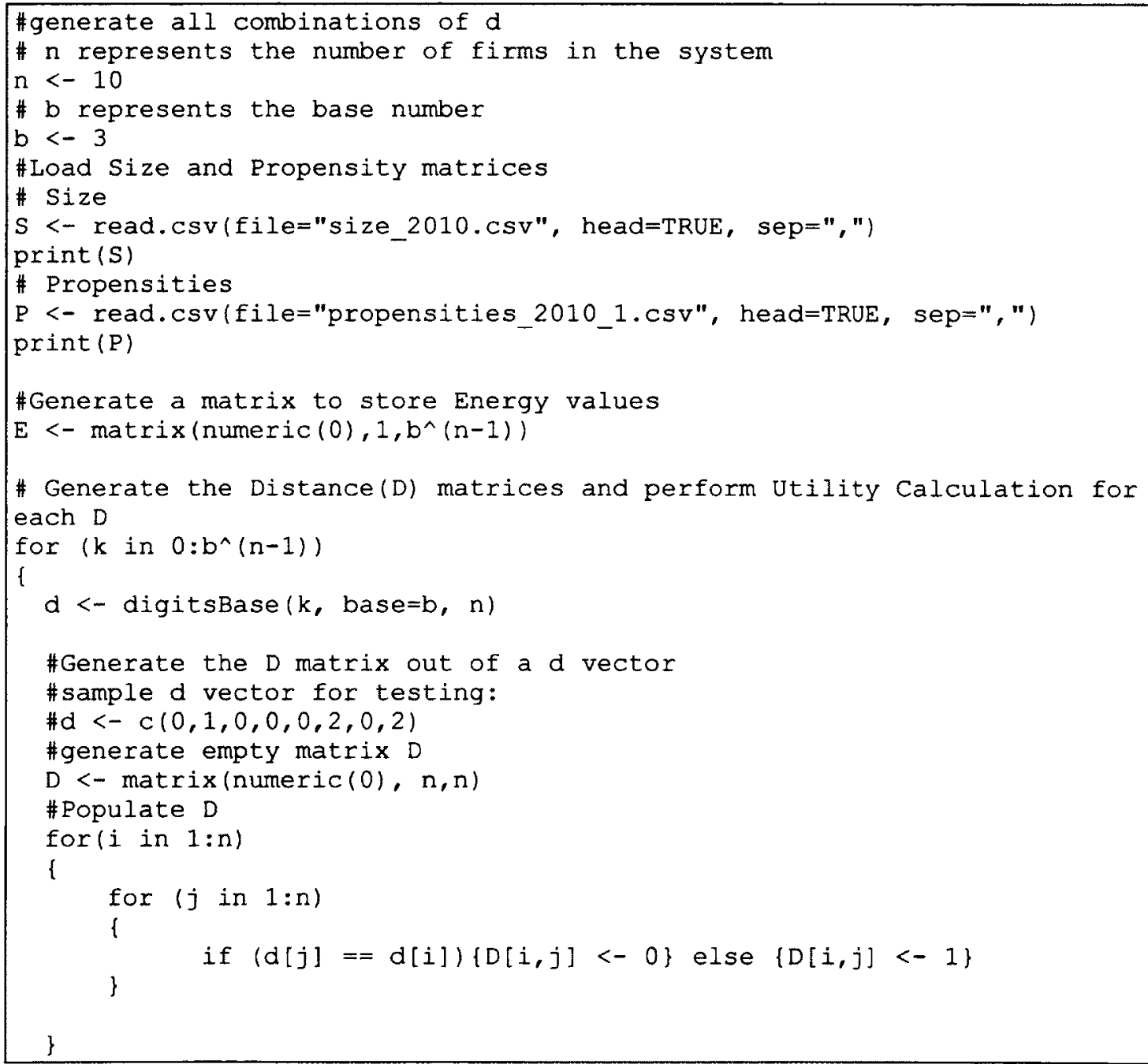




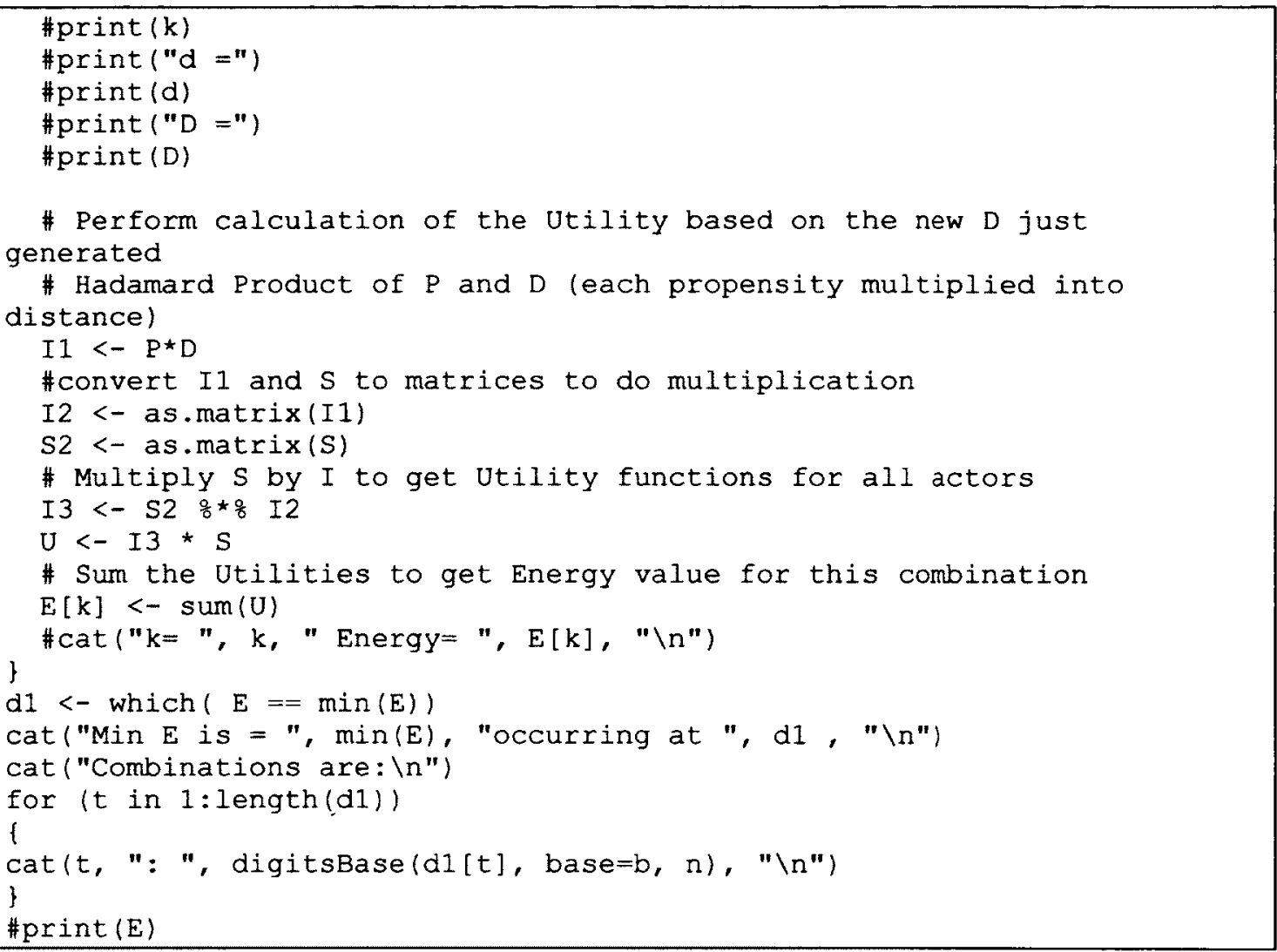




\section{References}

Axelrod, R., Mitchell, W., Thomas, R.E., Bennett, D.S., \& Bruderer, E. 1991. A

Landscape Theory of Alliances with Application to Standards Setting. Ann Arbor, MI:

University of Michigan, School of Business Administration.

Axelrod, R. \& Bennett, D. S. 1993. A Landscape Theory of Aggregation. British Journal of Political Science, 23(2): 211-233.

Axelrod, R., Mitchell, W., Thomas, R.E., Bennett, D.S., \& Bruderer, E. 1995. Coalition

Formation in Standard-Setting Alliances. Management Science, 41(9):1493-1508.

Basole, R. 2009. Visualization of interfirm relations in a converging mobile ecosystem.

Journal of Information Technology, 2009:1-16.

Basole, R. 2009. Structural Analysis and Visualization of Ecosystems: A Study of Mobile

Device Platforms Proceedings of the Fifteenth Americas Conference on Information Systems.

Basole, R., \& Karla J. 2011. On the Evolution of Mobile Platform Ecosystem Structure and Strategy. Business and Information Systems Engineering, 3(5): 313-322.

Boudreau, K. 2011. Let a Thousand Flowers Bloom? An Early Look at Large Numbers of Software App Developers and Patterns of Innovation. Organization Science, 22(5):119.

Galam, S. 1998. Comment on 'A Landscape Theory of Aggregation'. British Journal of Political Science, 28(2): 411-412.

Gandhewar, N., \& Sheikh, R. 2011.Google Android: An Emerging Platform for Mobile

Devices. International Journal on Computer Science and Engineering, 3(2):12-17. 
Gueguen, G., \& Isckia, T. 2009. The Borders of Mobile Handset Ecosystems: Is Coopetition Inevitable? Lecture Notes of the Institute for Computer Sciences, Social Informatics and Telecommunications Engineering, 12(1):45-54.

Iansiti, M., \& Levien, R. 2004. Strategy as Ecology. Harvard Business Review, 82(3): 68-78.

Kenney, M., \& Pon, B. 2011. Structuring the Smartphone Industry: Is the Mobile Internet OS Platform the Key?.Journal of Industry, Competition and Trade, 11(3):239-261.

Lin, F., \& Ye, W. 2009. Operating System Battle in the Ecosystem of the Smartphone Industry International Symposium on Information Engineering and Electronic Commerce.

Moore, J.F. 1993. Predators and Prey: A New Ecology of Competition. Harvard Business Review, 71(3): 75-86.

Moore, J.F. 2005. Business ecosystems and the view from the firm. The Antitrust Bulletin, 51(1): 31-75.

Weiss, M., \& Gangadharan, G.R. 2009. Growth of the Mashup Ecosystem. Unpublished paper, Carleton University, Ottawa and Telematica Institute, Enschede. 